\title{
REVIEW
}

\section{A compilation of precursor times of earthquakes in Taiwan}

\author{
Jeen-Hwa Wang *
}

Institute of Earth Sciences, Academia Sinica, Taipei City, Taiwan

\begin{abstract}
Article history:
Received 10 June 2021

Revised 9 July 2021

Accepted 12 July 2021

Keywords:

Earthquake prediction, Earthquake precursors, Precursor time, Earthquake magnitude

Citation:

Wang, J.-H., 2021: A compilation of precursor times of earthquakes in Taiwan. Terr. Atmos. Ocean. Sci., 32, 411-441, doi: 10.3319/ TAO.2021.07.12.01
\end{abstract}

\begin{abstract}
The precursor time, $T$, is the time interval between the occurrence time of a precursor and that of a forthcoming earthquake with local magnitude, $M_{L}$. The precursors are classified into four types of earthquake prediction with different time windows: long-term prediction ( $T=3$ to 10 years); intermediate-term prediction ( $T$ $=6$ months to 3 years); short-term prediction ( $T=8$ days to 6 months); and imminent prediction ( $T \leq 7$ days). Since the 1999 Chi-Chi earthquake, the precursors for numerous earthquakes in Taiwan have been observed and studied. The values of $T$ and $M_{L}$ are compiled from scientific literature. The plots of $T$ versus $M_{L}$ are made for some precursors when the data sets are large with the values of $T$ for respective events. Such precursors are the $b$-value anomalies, foreshocks, thermal infrared radiation anomalies, geochemical composition changes, radon changes, $\gamma$-ray emission anomalies, and total electron content (TEC) anomalies. There is a positive correlation between $T$ versus $M_{L}$ for the $b$-value anomalies, foreshocks, Rn changes, and $\gamma$-ray emissions. The relationship of $\log (T)$ versus $M_{L}$ is also inferred for $\mathrm{Rn}$ changes. The precursor time for Rn changes is positively correlated with that for $\gamma$-ray emissions. The time difference between the precursor time for Rn changes and that for $\gamma$-ray emissions is positively correlated to $M_{L}$. However, the plots for thermal infrared radiation, geochemical composition changes, and TEC anomalies are quite scattered and thus not any correlation can be obtained. The positive correlations between $T$ and $M_{L}$ or some precursors suggest the possibility of earthquake prediction in future.
\end{abstract}

\section{INTRODUCTION}

The earthquake rupture processes are considered to be preceded by a complex nucleation stage in which physical and chemical precursors might happen. Reports of precursors (e.g., Rikitake 1968; Turcotte 1991; Uyeda et al. 2011; Ouzounov et al. 2018a) show more than twenty different types. The precursors may be further classified into four categories: (1) mechanical precursors, including stress orientation changes, seismicity pattern changes, seismic quiescence, foreshock activities, crustal deformations, $b$-value anomalies, changes of seismic-wave velocities, hydrological changes, slow-slip events, infrasound, gravity, heat, nucleation phase, etc.; (2) electromagnetic (EM) precursors, including anomalous ground electric resistivity and

\footnotetext{
* Corresponding author

E-mail:jhwang@earth.sinica.edu.tw
}

conductivity, earthquake lights, thermal infrared emissions or long-wave radiation, geoelectric fluctuations, geomagnetic fluctuations, cloud-to-ground lightning, EM emissions from extremely low frequency (ELF) to very high frequency (VHF), anomalous sub-ionospheric VLF/LF signals, anomalies of ionospheric total electron content (TEC) and $f_{0} F_{2}$, etc.; (3) chemical precursors, including changes of geochemical compositions, radon concentration changes, gamma $(\gamma)$ ray emissions, etc.; and (4) biological precursors, including anomalous behavior of animals, humans, and plants.

The time interval between the occurrence of a certain precursor and that of the forthcoming earthquake is called the precursor time, $T$ (Wang et al. 2016). The precursor time may be dependent upon the magnitude of a forthcoming earthquake and varies in different seismogeniczone structures which may be distinct in different tectonic 
provinces. Based on the time windows, Wallace et al. (1984) and Kisslinger (1989) first used 'long-term' ( $T=$ a few years to a few decades), 'intermediate-term' ( $T=$ a few weeks to a few years), and 'short-term' ( $T<$ a few weeks) to show the windows of prediction. Of course, it is difficult to define the exact time windows because they may vary in different seismogenic zones. Based on the occurrence times of observed precursors, Wang (2021b) defined five types of earthquake prediction with different time windows for earthquakes in Taiwan: very-long-term prediction ( $T>$ ten years or longer); long-term prediction ( $T=$ three to ten years); intermediateterm prediction ( $T=$ six months to three years); short-term prediction ( $T=$ eight days to six months); and imminent prediction ( $T \leq$ seven days). The very-long-term prediction is based on earthquake recurrence that inferred from historical documents and data from geological trenching surveys. Since the recurrence times for $M \geq 6$ earthquakes are usually hundred years or even thousand years, for example, > 3000 years for the 2008 Wenchung, China earthquake (Ran et al. 2013). After an earthquake happened along a fault, the contemporary geologists estimate the recurrence times of the event and past ones that had ruptured the fault from the field data of geological trenching borehole drilling and from historical documents. Since the next event will occur in the far future due to a very long recurrence time, the contemporary earthquake scientists cannot observe and study its precursors. Hence, in this review paper we will focus on the studies of the precursors that appeared within ten years before earthquakes in Taiwan.

Several authors (Tsai et al. 1977; Wu 1978; Tsai 1986) proposed that Taiwan is located at an oblique collision zone between the Eurasian plate (EP) and the Philippine Sea plate (PSP). The collision boundary between the two plates is almost along the Longitudinal Valley (LV) which is schematically displayed by a thin line marked with 'LV' in Fig. 1. The PSP has been moving northwestward at a speed of $\sim 80$

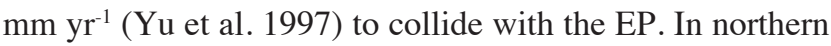
Taiwan, the subduction zone of the PSP is beneath the EP. In southern Taiwan, the EP moves from west to east and the subduction zone of the EP is beneath the PSP. Active orogeny due to the collision of these two plates causes complex tectonics and geological features in the region. The complex tectonics has resulted in high and heterogeneous seismicity in Taiwan (Wang 1988a, 1998). Seismological studies have

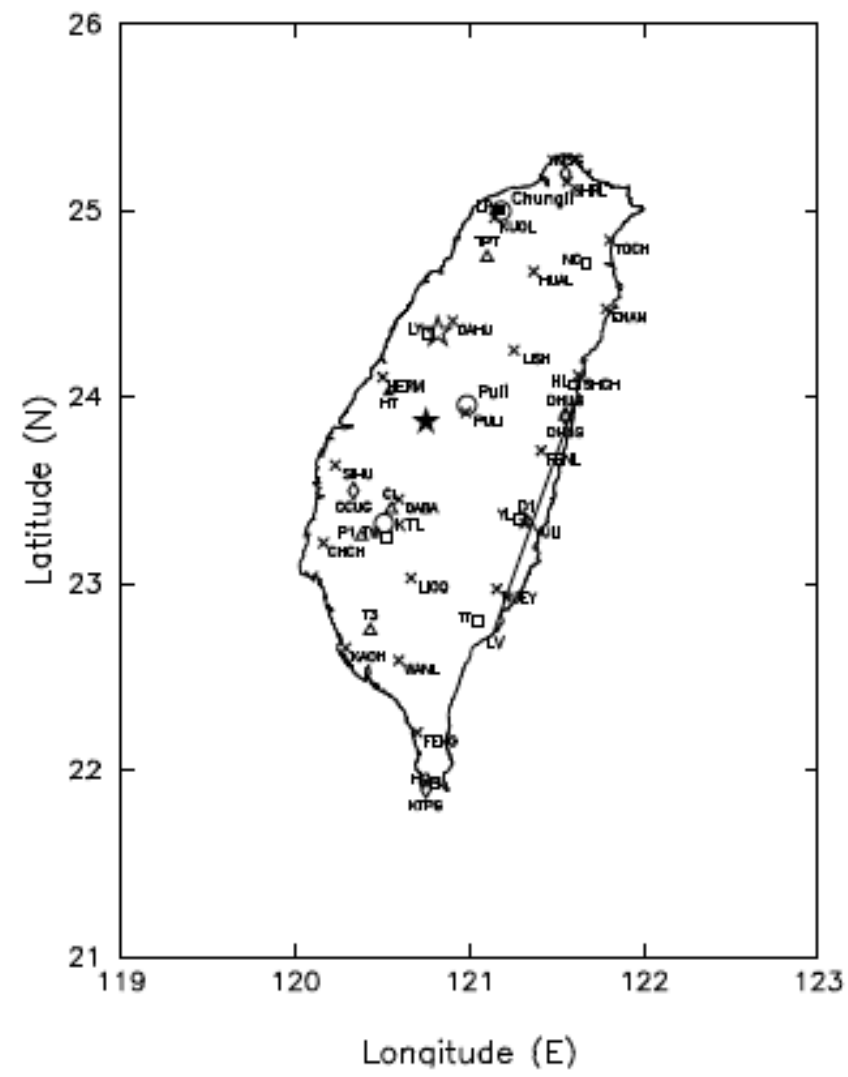

Fig. 1. The figure shows the epicenter (in an open star) of the $1935 M_{s} 7.2$ Hsinchu-Taichung earthquake and that (in a solid star) of the $1999 M_{w}$ 7.6 Chi-Chi earthquake. The geomagnetic LP station is denoted by a solid square and those at other seven stations are displayed by open squares. The groundwater HP station is shown by a solid triangle. The geochemical monitoring stations are shown by open triangles. The $\gamma$-ray monitoring stations are shown by open diamond symbols. The geoelectric field monitoring stations are shown by crosses. Three geographic places, i.e., Chungli, Puli, and Kuantzeling (KTL), are displayed by larger-sized open circles. A thin line marked with 'LV' in eastern Taiwan represents the Longitudinal Valley. 
been conducted in Taiwan for more than one century (Wang 1998). Different types of seismic, geodetic, geophysical, and geochemical stations have been constructed in the region (Yeh et al. 1981; Wang 1989; Shin and Chang 2005; Fu and Lee 2018; Chen and Chen 2016). Figure 1 also displays the stations that are used in this study and described below. Numerous earthquakes, including the 20 April 1935 $M_{s} 7.2$ Hsinchu-Taichung earthquake (e.g., Hsu 1971; Miyamura 1985) and the 20 September $1999 M_{L} 7.3\left(M_{w} 7.6\right)$ Chi-Chi earthquake (e.g., Ma et al. 1999; Shin and Teng 2001; Wang et al. 2005b; Wang 2019) caused severe damage in the region. The two events are displayed in Fig. 1: an open star for the former and a solid star for the latter. To reduce seismic hazards, the earthquake prediction research is hence important in the region.

In past several decades, Taiwan's earthquake scientists collected numerous data of different types of earthquake precursors. Wu and Feng (1975) made the first study of precursor for Taiwan's earthquake. They reported that the gas well pressure fluctuations occurred about 9 days before the 18 January $1964 M_{L} 6.3$ Tainan-Chiayi (Paiho) earthquake. The 10 May $1983 M_{L} 6.4\left(M_{D} 5.7\right)$ Taipingshan earthquake is the first event for which several different types of precursors were reported: $b$-value anomalies and foreshocks by Chen and Wang (1984) and Chen et al. (1990), changes of duration ratios of seismograms by Wang (1988b), and radon ${ }^{222} \mathrm{Rn}$ ) concentration changes by Liu et al. (1984). The radon $\left({ }^{222} \mathrm{Rn}\right)$ is simply denoted by $\mathrm{Rn}$ hereafter.

An abnormal increase in seismicity during 1977 to 1978 in Taiwan encouraged earthquake scientists of Taiwan and USA to promote a joint research program of earthquake precursors under the sponsors by National Science Council (NSC), ROC and U.S. Geological Surveys, USA. The principal investigators were Director Y.-B. Tsai of Institute of Earth Sciences (IES), Academia Sinica, ROC and Academician Prof. T.-L. Teng of University of Southern California (USC), USA. Tsai et al. (1983) reviewed the preliminary studies of precursors done by the colleagues of IES and USC before 1983. However, they only described the installation of instruments and the studies of observations of five geophysical and geochemical phenomena (including spatial and temporal variations in micro-earthquakes, horizontal crustal deformations in eastern Taiwan, temporal variations in microgravity, temporal variations in geomagnetic total intensities, and changes of Rn concentrations in geothermal waters). Although the authors tried to correlate the changes of gravity and $\mathrm{Rn}$ concentrations with some earthquakes, they did not obtain positive correlations.

The 1999 Chi-Chi earthquake ruptured the Chelungpu fault in central Taiwan. Its epicenter is displayed with a solid star in Fig. 1. Unfortunately, this event was not predicted or forecasted by Taiwan's earthquake scientists because the Chelungpu fault was classified to be the Type-II active fault by the Central Geological Survey before 1999 .
After the earthquake, numerous earthquake scientists examined the recorded data and tried to search for the possible precursors before the event. Under sponsor by both Ministry of Education and NSC, a research program, entitled 'the Integrated Search for Taiwan Earthquake Precursors (iSTEP)', was conducted by the earthquake scientists of National Central University (NCU) from April 2002 to July 2005 (see Tsai et al. 2004). This program includes mainly five major components, i.e., identification of potential seismological, geomagnetic, geodetic, and ionospheric precursors and statistical testing of any identified precursors. Tsai et al. $(2004,2006)$ reviewed the studies of numerous precursors, especially for the Chi-Chi earthquake, under the iSTEP program. In addition to the studies shown in the Tsai et al. (2004, 2006), Tsai et al. (2018) reviewed some chemical precursors done by geochemists of National Taiwan University. In addition, Liu et al. (2000) reviewed the anomalies of ionospheric $f_{o} F_{2}$ for $M_{L} \geq 5$ earthquakes. Liu et al. (2004a) reviewed the anomalies of ionospheric TEC for $M_{L} \geq 6$ earthquakes. Liu et al. (2006) reviewed the seismogeomagnetic anomalies for $M_{L} \geq 5$ earthquakes. Liu et al. (2015) reviewed the anomalous lightning activities for $M_{L}$ $\geq 5$ earthquakes. Chen et al. (2009) reviewed the preseismic geomagnetic anomalies. Chen et al. (2013b) reviewed the groundwater level changes for $M_{L} \geq 6$ earthquakes. Fu and Lee (2018) reviewed geochemical precursors.

Before directly applying the observed precursors to predict a forthcoming earthquake, earthquake scientist must deeply study the precursors through several steps. First, we must compile all observed precursors and their precursor times for related earthquakes from scientific literature. For example, Cicerone et al. (2009) compiled several types of precursors for a larger number of world-wide earthquakes, including the 1999 Chi-Chi earthquake and several largersized events of Taiwan. Their results will be useful for earthquake prediction research. Secondly, we may test physically or statistically the reliability of observed precursors. One of the ways is to study if there is a correlation between the precursor time and earthquake magnitude or not. Thirdly, we must explore their possible generation processes. Finally, we may develop prediction models for respective categories of precursors or even build a unified prediction model for all precursors. According to the respective models or the unified model, we may be able to predict an earthquake.

Since 1975, there have been a large number observations of earthquake precursors in Taiwan. It is necessary to compile the precursors and their precursor times. For the 1999 Chi-Chi earthquake, Wang (2021b) reviewed the observed precursors, compiled their precursor times from scientific literature, and discussed their reliability. In this study, we will compile the precursor times of long-term, intermediate-term, short-term, and imminent precursors of Taiwan's earthquakes from given scientific literature. The possible correlations between the precursor time and 
earthquake magnitude for some precursors will also be studied. Since the precursors and related precursor times of the 1999 Chi-Chi have been explained and discussed in details by Wang (2021b), the information of precursors of the event will be simply described below. The earthquakes of Taiwan were quantified with different magnitude scales (Wang and Miyamura 1990; Wang 1992, 1998; Shin 1993), i.e., Hsu's magnitude $M_{H}$, duration magnitude $M_{D}$, surface-wave magnitude $M_{s}$, moment magnitude $M_{w}$, and local magnitude $M_{L}$, in different time periods. In the followings, the earthquake magnitude is unified to be the local magnitude, $M_{L}$, determined by the Central Weather Bureau (CWB) (Shin 1993). The focal depth of an earthquake is denoted by $d$ (in $\mathrm{km}$ ) and the epicentral distance from an event to an observation station is shown by $\Delta$ (in $\mathrm{km}$ ). Almost all authors took the earthquake data (including occurrences times, locations, and magnitudes) from the CWB. Hence, the source of data will not be mentioned again below.

\section{LONG-TERM PREDICTION}

\subsection{Mechanical Precursors}

\subsubsection{Stress Orientation Changes}

$\mathrm{Wu}$ et al. (2010) determined the stress axes from the fault plane solutions of 4761 events of Taiwan during 1991 to 2007. They denoted the orientation of the maximum horizontal compressive stress axes to be SH. They recognized a counterclockwise rotation of SH in the entire ruptured area between 1991 and 1999 before the 1999 Chi-Chi earthquake. From the same data set, Hsu et al. (2010) also inferred changes of the distribution of the coefficients of friction and that of the pore pressures during 1991 to 1999. From the two studies, the precursor time is $\sim 9$ years (listed in Table 1).

\subsubsection{Temporal Variation in Seismicity Pattern}

Mogi (1981) first studied seismicity patterns, including seismic quiescence, prior to $M \geq 6$ earthquakes in western Japan. The description about the studies of seismicity patterns can see Wang (2021b). By applying the pattern informatics (PI) algorithm (Rundle et al. 2003; and cited references herein) to analyze $M_{L} \geq 3.4$ earthquakes with $d \leq 20 \mathrm{~km}$, Chen et al. (2005a) found anomalous changes of seismicity and seismic quiescence over a time period of $\sim 6$ years before the 1999 Chi-Chi earthquake. Wu and Chen (2007) computed the standard normal deviate Z-values (Meyer 1975) for the temporal variation of monthly numbers of $M_{L} \geq 2$ events occurring from 1994 to 2006. They found that the areas with relatively high seismicity in eastern Taiwan from 1994 to 1998 became abnormally quiet before the mainshock; while the area with relatively low seismicity from 1994 to the oc- currence of the mainshock in central Taiwan showed unusually active after the mainshock. Previous two studies suggest that the precursor time for seismicity pattern change is $\sim 6$ years (listed in Table 1).

From the calculated PI values of seismicity before the 26 December 2006 Pingtung offshore doublet earthquakes with $M_{L}=6.7$ and 6.4 , Wu et al. $(2008,2012)$ found that seismicity changed in March 2004 about 2.7 years before the mainshock. The precursor time is 2.7 years (listed in Table 1). Wen and Chen (2017) applied the region-time-length (RTL) algorithm to investigate the seismicity rate changes prior to the 5 February $2016 M_{L} 6.6$ Meinong earthquake in southern Taiwan. Seismic quiescence occurred soon after the 26 February $2012 M_{L} 6.4$ Wutai earthquake and then lasted until the occurrence of the 2016 Meinong earthquake, and the latter happened near a patch that was recognized as the seismic quiescence by Wen and Chen (2017). Hence, the precursor time is 4 years (listed in Table 1).

\subsection{3 $b$-Value Anomaly}

The $b$-value anomalies before earthquakes have also been studied by numerous researchers (see Wang et al. 2015, 2016; and cited references therein). As displayed in Fig. 2, the abnormal $b$-value started at $t_{0}$ and lasted until the occurrence of the mainshock. Thus, the total time period of abnormal $b$-values may be several years. Usually, there are two precursor times of abnormal $b$-values in literature (e.g., Wang et al. 2016): the first one is measured from the beginning of an increase in $b$-value to the occurrence time of an earthquake and the second one (denoted $T_{p}$ here) done from the time of a decrease in $b$-value from its peak. Wang et al. (2016) compiled the values of $T$ and $T_{p}$ from the temporal variations in $b$-values of 45 earthquakes with $3 \leq M \leq 9$ occurred in various tectonic provinces. Their results show that both $T$ and $T_{p}$ increase with $M$. Hence, it is fine to take either $T$ or $T_{p}$ as the precursor time. From Fig. 2, the precursor time $T$ includes both the increase and decrease in $b$-values, while the precursor time $T_{p}$ includes only the decrease in $b$-values. Based on the model proposed by Wang (2016), $T$ may represent the whole process of variation in $b$-value. Hence, I prefer to $T$ rather than $T_{p}$ as the precursor time of the $b$-value anomalies.

Before the 20 May $1983 M_{L} 6.4\left(M_{D} 5.7\right)$ Taipingshan earthquake, Chen and Wang (1984) and Chen et al. (1990) estimated the average $b$-value in every one year for seismicity from 1973 to 1982 . Results show that in the source area the $b$-values gradually increased from 1978 and reached its peak in 1981, and then decreased. However, in the surrounding region of the source area the $b$-values increased markedly about 4.4 years before the mainshock and then decreased before it. The precursor time is $\sim 4.4$ years (listed in Table 1). 
Based on the time series of $b$-values for $M_{L} \geq 2.0$ events with $d \leq 40 \mathrm{~km}$ from 1 January 1994 to 31 August 1999 in three regions surrounding the source area of the ChiChi earthquake, Tsai et al. (2006) assumed that the $b$-value anomalies in northern and middle regions are a possible precursor of the mainshock. The precursor time is $\sim 6$ years (listed in Table 1).

Wu and Chiao (2006) compiled a data set (called the W\&C data set hereafter) consisting of $66069 M_{L} \geq 2.0$ events with $d \leq 40 \mathrm{~km}$ from January 1994 to the 1999 ChiChi earthquake. The time series of $b$-values calculated from this data reveal a decrease of $b$-value and an increase of seismicity in the area surrounding the source about 9 months before the earthquake. Their results give $T_{p}=9$ months. Chan et al. (2012) also measured the average value of $T(\approx 3$ years) for 23 Taiwan's earthquakes with $M_{L} \geq 6$, including the Chi-Chi earthquake, yet they did not provide the value of $T$ for each event.

Wu et al. (2008) measured the $b$-values for the $26 \mathrm{De}$ cember 2006 Pingtung offshore doublet earthquakes with $M_{L}=6.7$ and 6.4. Results show that the $b$-value changed about three years before the Pingtung doublets. Hence, the precursor time is 3 years (listed in Table 1).

\subsubsection{Changes in the $\boldsymbol{P}$-Wave Travel-Time Residuals}

Since Semenov (1969) first claimed that seismic-wave velocities decreased before an earthquake and then recovered after the event, numerous studies about anomalous seismic-wave travel-time residuals before earthquakes have been done (see Geller 1997; and cited references therein). The general pattern of temporal variation in $P$-wave traveltime residuals (denoted as $\delta t_{p}$ ) is simplified by a dashed line in Fig. 2. Lee and Tsai (2004) measured the mean values of $\delta t_{p}$ at 11 seismic stations around the source area in three time periods: (1) the first period from 1 January 1991 to 31 December 1993; (2) the second period from 1 January 1994 to 21 September 1999; and (3) the third period from 22 September 1999 to 31 December 2002. The first and second periods were before the mainshock and the third one after the mainshock. The ranges of differences between the mean values of $\delta t_{p}$ in the first period and those in the second one are: from $+0.009 \pm 0.068 \mathrm{sec}$ to $+0.273 \pm 0.144 \mathrm{sec}$ at 8 stations immediately west of the Chelungpu fault; from $-0.053 \pm 0.083 \mathrm{sec}$ to $-0.117 \pm 0.087 \mathrm{sec}$ at two stations southeast of the fault; and from $-0.149 \pm 0.151$ at a station far west of the fault. Results show that $\delta t_{p}$ increased at the stations immediately west of the Chelungpu fault about six years before the earthquake. It implies that $P$-wave velocity, $v_{p}$, began to decrease (like the left segment in Fig. 2) in 1994, about six years before the mainshock. The precursor time for anomalous $\delta t_{p}$ or anomalous $v_{p}$ is $\sim 6$ years (listed in Table 1).

\section{INTERMEDIATE-TERM PREDICTION}

\subsection{Mechanical Precursors}

\subsubsection{Crustal and Surface Deformations}

From the ERS-2 radar images, Tsai et al. (2006) found that surface deformation began at least three years before the earthquake in an area immediately to the west of the northern segment of the fault. Hence, the precursor time for surface deformations is $\sim 3$ years (listed in Table 1 ).

\subsubsection{Seismicity Pattern, Seismic Quiescence, and Foreshocks}

Foreshocks are usually considered as one of the most significant premonitory phenomenon of a forthcoming earthquake, because they may accurately pinpoint the time and location of the mainshock. For example, foreshocks played the key role on the successful prediction of the 4 February 1975, Haicheng, PRC, earthquake (e.g., Wu et al. 1976).

Before the 20 May $1983 M_{L} 6.4\left(M_{D} 5.7\right)$ Taipingshan earthquake, Chen and Wang (1984) and Chen et al. (1990) observed two groups of foreshocks. The first one (called the forerunners here) occurred southeast of the source area from 1 September 1982 to 30 April 1983 about 8 months before the mainshock. The second one (i.e., the common foreshocks) took place within the source area on May 16 about four days before the mainshock. The precursor times are 8 months and 4 days, respectively, for the forerunners and common foreshocks (listed in Table 1).

$\mathrm{Wu}$ and Chiao (2006) calculated the standard normal deviate Z-value (Meyer 1975) for seismicity before and after the 1999 Chi-Chi earthquake. Results exhibit that a decrease of seismicity rate started in January 1999 and lasted about 9 months, until the occurrence of the mainshock. They also claimed that the appearance of seismic quiescence was attributed essentially to a remarkable decrease in smaller-sized events with $M_{L}<4$. Wu and Chen (2007) also observed that the monthly number of events remarkably decreased in the source area from January 1999 to the occurrence of the mainshock. Their observation is similar to that established in Wu and Chiao (2006). From the studies of the two groups of researchers, the precursor time for seismic quiescence is $\sim 9$ months (listed in Table 1). The decrease of $b$-values observed by $\mathrm{Wu}$ and Chiao (2006) is consistent with the seismic quiescence found by $\mathrm{Wu}$ and Chen (2007). This indicates the same mechanism for the two precursors.

Kawamura and Chen (2013) applied the EpidemicType Aftershock-Sequences (ETAS) model to study $M_{L} \geq$ 2.4 events before the Chi-Chi earthquake. They found that seismic quiescence appeared within several areas near the mainshock epicenter from 1 January 1998 to 20 September 1999. The first seismic quiescence appeared about 21 months before the mainshock. Hence, the precursor time for 


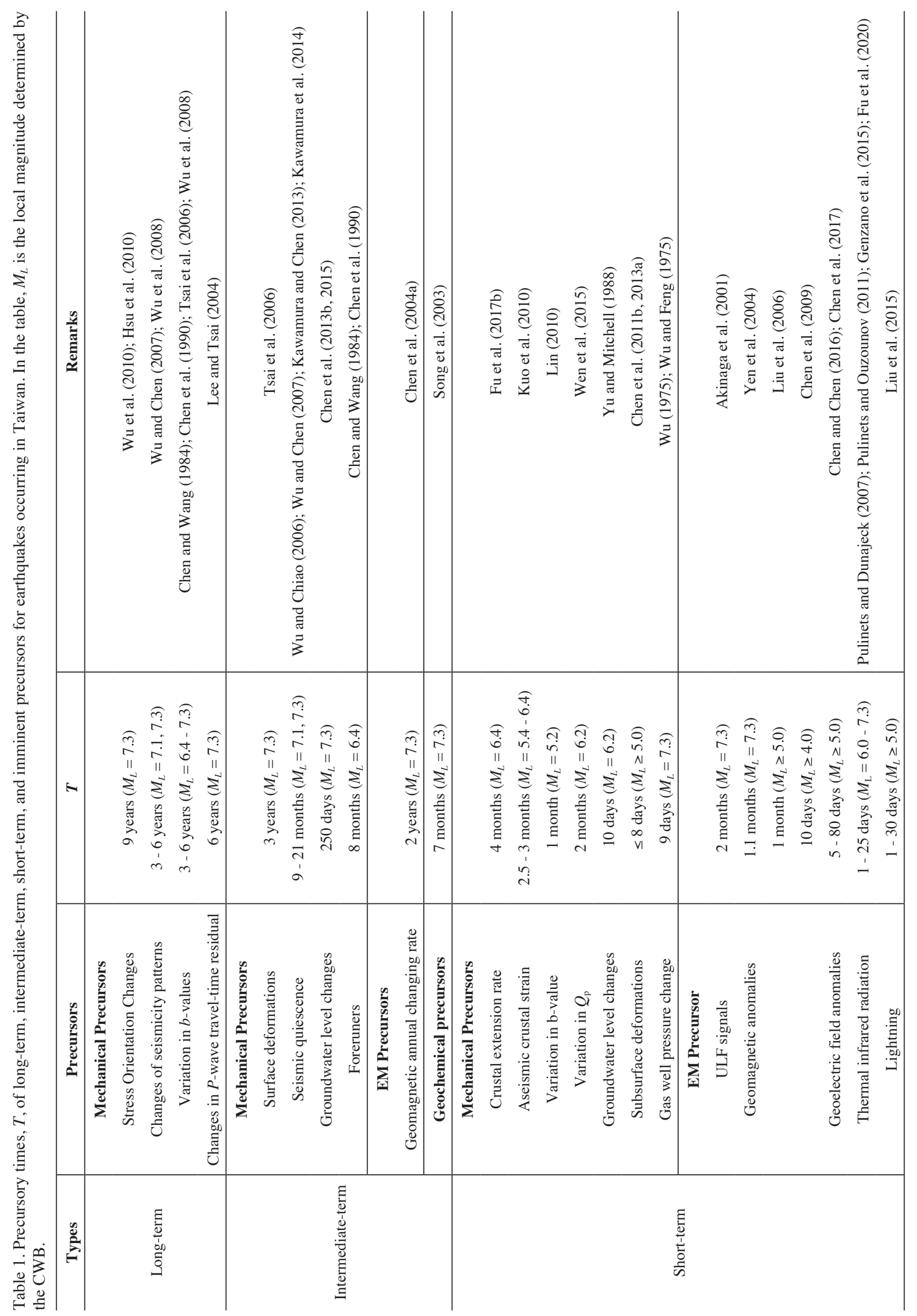




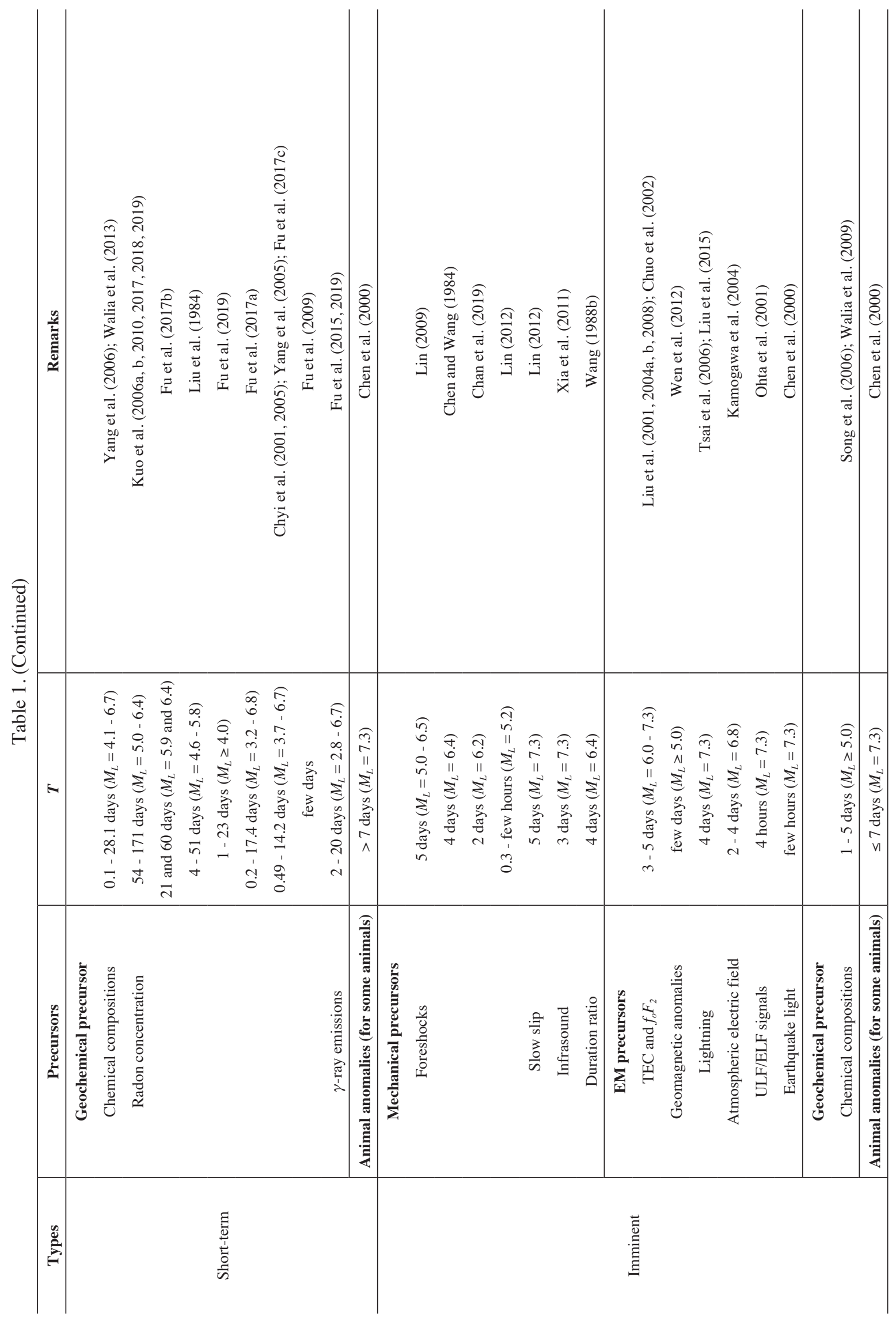




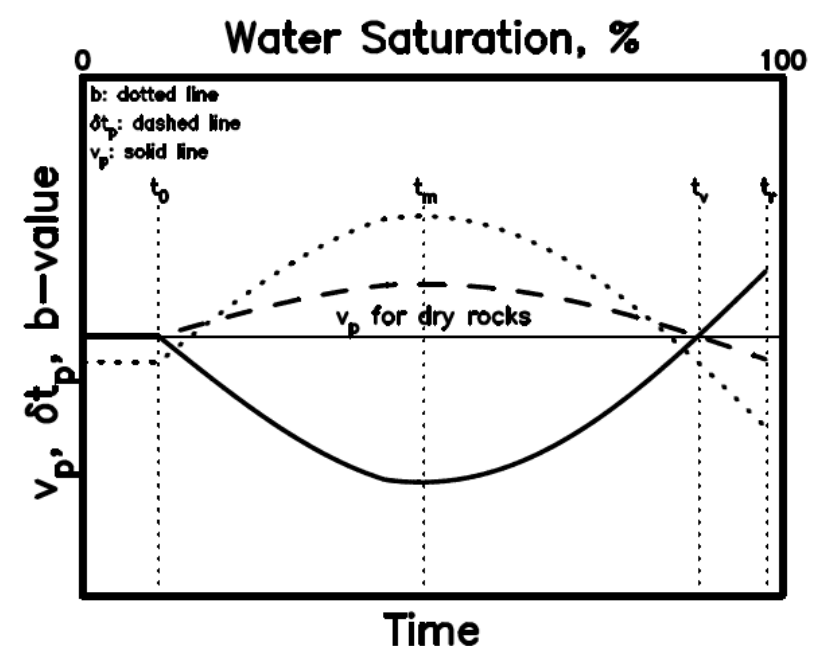

Fig. 2. The temporal variations in water saturation, $v_{p}, P$-wave travel-time residue, $\delta t_{p}$, and $b$-value. The horizontal line denotes the $v_{p}$ for dry rocks. The solid line, dashed line, and dotted line represent $v_{p}, \delta t_{p}$, and $b$-value, respectively (modified from Wang 2016).

seismic quiescence is 21 months (listed in Table 1). Their precursor time is 2.3 times longer than that observed by the previous two groups of researchers. The difference in the occurrence times of seismic quiescence between $\mathrm{Wu}$ and Chiao (2006) and Kawamura and Chen (2013) may be due to the uses of different data sets. The former group took earthquakes around the Taiwan Island, while the latter one selected those only in several smaller areas. Hence, the seismic quiescence obtained by the former group may be just an average effect around Taiwan, while that reported by the latter group actually reflects the property of the source area.

Kawamura et al. (2014) applied three approaches, e.g., the ETAS model, the PI method, and the ZMAP method that is similar to the Z-value method to study seismicity pattern change in a broad area before two Nantou earthquakes. The first event with $M_{L}=6.2$ occurred on 27 March 2013 and the second one with $M_{L}=6.3$ happened on 2 June 2013 . They found that before the first event, seismic quiescence appeared in three areas surrounding the epicenter. The first seismic quiescence appeared about $\sim 1.5$ years before the event and the second and third ones happened later. The precursor time is $\sim 1.5$ years or 18 months (listed in Table 1). Clearly, the precursor time of seismic quiescence for the Nantou earthquakes are shorter than that for the 1999 ChiChi earthquake. However, Wen and Chen (2017) found the precursor time of seismic quiescence before the 2016 $M_{L} 6.4$ Meinong earthquake is 4 years. This value is much longer than that of the Nantou events. Hence, from these studies we cannot see a positive correlation between precursor time and $M_{L}$ for seismic quiescence for earthquakes in Taiwan.

\subsubsection{Groundwater Level Changes}

Preseismic groundwater level changes, $\delta h$, have been observed in both confined and unconfined aquifers (e.g., Roeloffs et al. 1997; and cited references therein). Since the groundwater level changes have been observed only in unconfined aquifers in Taiwan, the mechanism is described below. The change in reservoir fluid pressure, $\delta p$, is related to an incremental change in volumetric strain, $\delta \varepsilon$, that is positive for tension (or dilatation) and negative for compression. Rice and Cleary (1976) related the groundwater level $\delta h$ to $\delta \varepsilon$ by $\delta h=-\left(H_{s} / \psi\right) \delta \varepsilon$ where $H_{s}$ is the saturation thickness of the aquifer and $\psi$ is the porosity of fault-zone rocks. For example, the water level is $0.5 \mathrm{~cm}$ per $10^{-6}$ strain for a $100 \mathrm{~m}$ saturated aquifer with $\psi=0.02$ (Roeloffs 1988).

According to the anomalous frequency characteristics of groundwater level from the corrected data at 54 wells, Chen et al. (2013b, 2015) observed abnormally changed groundwater levels at $78 \%(=42 / 54)$ of wells, which are located to the west of the mainshock epicenter, before the ChiChi earthquake. For example, at the Huatang (HT) station (shown with an open triangle in Fig. 1) the temporal variation in groundwater level from 1 August 1997 to 19 September 1999 is schematically displayed by thick line segments in Fig. 3 that is simplified from a figure in Chen et al. (2015) and the dashed line denotes the regular decrease in groundwater level. Clearly, the groundwater level decreased about 250 days (from 17 January), reached the bottom ( - $1.5 \mathrm{~m})$ then immediately increased about 130 days (from 18 May), and returned to a local maximum about 13 days (from 7 September) before the mainshock. For all stations in consideration, they observed that groundwater level changes ranged from 2 to $4 \mathrm{~m}$. The precursor time for groundwater level changes is $\sim 250$ days (listed in Table 1).

Chen et al. (2013b) examined variations of amplitude of water-level changes at a particular frequency band between 0.02 and 0.04 day $^{-1}$ for $M_{L}>6$ earthquakes in Taiwan from 1 August 1997 to 31 December 2009. They found that 


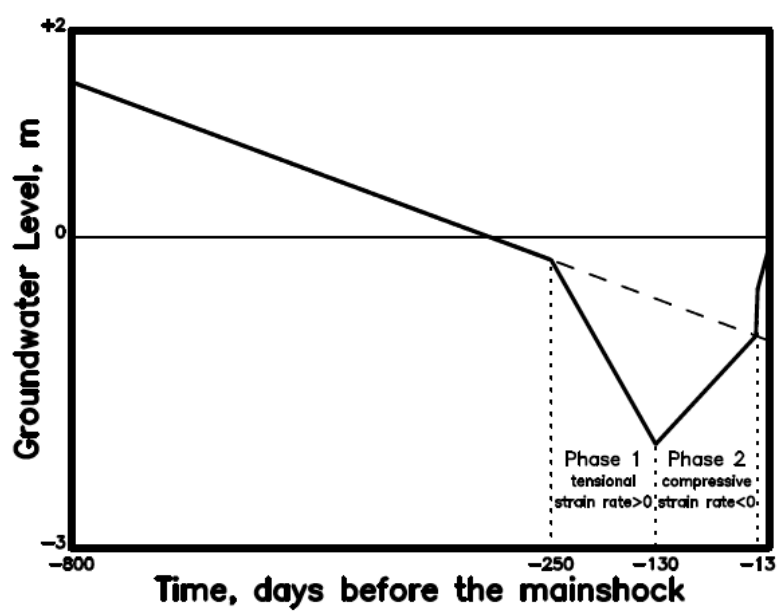

Fig. 3. A temporal variation of groundwater level after air-pressure correction in the third aquifer at the HT station from 1 July 1997 to 21 September 1999. The dash line suggests that a decrease tendency of about $-0.7 \mathrm{~m} \mathrm{yr}^{-1}$ in the groundwater level. Phase 1 and Phase 2 represent, respectively, the fall and rise in the groundwater level prior to the Chi-Chi earthquake (after Wang 2021b).

the enhanced amplitudes in the frequency band were consistently observed prior to the 27 July $1998 M_{L} 6.2$ Reili and 5 November $2009 M_{L} 6.2$ Mingjian earthquakes during the 12.5-year study period. However, they did not provide the precursor time.

\subsection{Electromagnetic Precursors: Geomagnetic Annual Changing Rate}

Gokhberg et al. (1982) first took the EM emissions in the low-frequency (LF) band (30 - $300 \mathrm{kHz})$ as an earthquake precursor. Since then, EM signatures in different frequency bands, i.e., from extremely low frequency (ELF) band $(3-30 \mathrm{~Hz})$ to very high frequency (VHF) band (30 - $300 \mathrm{MHz}$ ), have been long and widely considered as a promising candidate of an earthquake precursor (Uyeda et al. 2009; Shrivastava 2014; Ouzounov et al. 2018a, b; Venegas-Aravena et al. 2019; and cited references therein). The signals in two lower frequency bands, i.e., ELF and VLF (3 - $30 \mathrm{kHz}$ ), are particularly promising. Several models were proposed to interpret the generation of EM emissions (see Molchanov and Hayakawa 1995; Wang 2021a; and cited references therein).

Since 1988, a geomagnetic network (abbreviated as the IESGN) consisting of 22 stations has been installed in Taiwan by the IES (Yeh et al. 1981). Among them, 8 stations are also equipped with continuous recording systems. Among the eight stations, the Lunping (LP) station (shown by a solid square in Fig. 1) is located at a low-seismicity area and thus commonly taken as a reference station, while others (shown by open squares in Fig. 1) are all located at the seismically active areas. Other seven stations are Liyu$\tan (\mathrm{LY})$, Tsengwen (TW), Neicheng (NC), Hualien (HL), Yuli (YL), Taitung (TT), and Hengchun (HC).

Chen et al. (2004a) took the LP station as a reference one for others and examined the temporal variations in the total geomagnetic field recorded at the eight stations from 1999 to 2001. Their results exhibit that a zero isoporic zone (ZIZ), which is defined as the annual change rate of geomagnetic parameters $\leq \pm 5 \mathrm{nT} \mathrm{yr}^{-1}$, appeared near the source area about 2 years before the 1999 Chi-Chi earthquake. Up to date, this precursor is the only one intermediate-term EM precursor that has been observed in Taiwan. The precursor time is $\sim 2$ years (listed in Table 1 ).

\subsection{Chemical Anomalies: Changes of Geochemical Compositions}

Changes in groundwater chemistry (including the hydrochemical precursors and geochemical precursors of hot springs) have long been considered as one of the significant precursors of earthquake prediction (Paudel et al. 2018; and cited references therein). The hydrochemical precursors, i.e., changes in groundwater compositions, include variations in stable isotope ratios of the dissolved gases (e.g., He/Ar, $\mathrm{CH} /$ $\mathrm{Ar}, \mathrm{N}_{2} / \mathrm{Ar},{ }^{3} \mathrm{He} /{ }^{4} \mathrm{He}$, etc.), $\mathrm{pH}$ values, electrical conductivity, radon activities, ion concentrations (e.g., $\mathrm{SO}_{4}^{-2}, \mathrm{NO}_{3}{ }^{-1}, \mathrm{Cl}^{-1}$, etc.), etc. The geochemical precursors of hot springs include mantle-derived $\mathrm{CO}_{2}$ with high ${ }^{3} \mathrm{He} /{ }^{4} \mathrm{He}\left(\sim 7 \mathrm{R}_{\mathrm{a}}\right)$, crustal $\mathrm{CO}_{2}$ with low ${ }^{3} \mathrm{He} /{ }^{4} \mathrm{He}\left(<0.2 \mathrm{R}_{\mathrm{a}}\right)$, crustal $\mathrm{CH}_{2}$ with low ${ }^{3} \mathrm{He} /{ }^{4} \mathrm{He}$ $\left(<0.2 \mathrm{R}_{\mathrm{a}}\right)$ and high He contents $(>50 \mathrm{ppm})$, and dissolved air in saturated groundwater with ${ }^{3} \mathrm{He} /{ }^{4} \mathrm{He}=1 \mathrm{R}_{\mathrm{a}}$ and very low He contents $(<1 \mathrm{ppm})$. Note that $\mathrm{R}_{\mathrm{a}}$ is the air ${ }^{3} \mathrm{He} /{ }^{4} \mathrm{He}$ ratio of $1.39 \times 10^{-6}$. The geochemical compositions and the ion species of the subsurface water bodies come from the underground reservoirs. Song et al. (2005) claimed that the major factors in determining if the chemical anomalies in the waters may be used as an earthquake precursor or not are the geological structures, the depths, and the size of reservoirs. Chen et al. (2004b) started the observations of geochemical 
compositions near active faults. Several authors (e.g., Chen et al. 2004b, 2005b; Fu and Lee 2018; Tsai et al. 1983, 2018) reviewed the studies of geochemical anomalies before earthquakes in Taiwan.

Song et al. (2003) analyzed the anions, e.g., $\mathrm{SO}_{4}{ }^{-2}$, and $\mathrm{NO}_{3}^{-1}$, of the bottled water (named as Chingjing water), which was pumped from wells at Puli (displayed by a larger-size open circle in Fig. 1), Nanton County in central Taiwan, from 1 December 1998 until after the event. Results show steady increases in concentrations of both sulfate $\left(\mathrm{SO}_{4}^{-2}\right)$ and nitrate $\left(\mathrm{NO}_{3}^{-1}\right)$ from the average constant levels, which were measured from 1 December 1998 to 31 March 1999, after 1 April 1999. The concentrations reached the peak with an excess of 129.9 and $94.7 \%$ in April 1999, then remarkably dropped from July 1999, and finally decreased until the mainshock. The precursor time for groundwater chemistry anomalies is $\sim 7$ months (listed in Table 1). Wang et al. (2005a) reported isotopic and hydrological changes prior to the Chi-Chi earthquake. But, they did not provide the times of changes.

\section{SHORT-TERM PREDICTION}

\subsection{Mechanical Precursors}

\subsubsection{Subsurface Deformations}

Kuo et al. (2010) estimated the aseismic crustal strain at the Antung hot spring prior to three events, i.e., the 10 December $2003 M_{L} 6.4\left(M_{w} 6.8\right)$ Chengkung earthquake with $d$ $=17.7 \mathrm{~km}$ and $\Delta=20 \mathrm{~km}$, the 1 April $2006 M_{L} 6.0\left(M_{w} 6.1\right)$ Taitung earthquake with $d=17.9 \mathrm{~km}$ and $\Delta=55 \mathrm{~km}$, and the 17 February $2008 M_{L} 5.4\left(M_{w} 5.0\right)$ Antung earthquake with $d=28.3 \mathrm{~km}$ and $\Delta=11 \mathrm{~km}$. The strain increased about $3,2.5$, and 2.5 months, before the 2003, 2006, and 2008 events, respectively. Hence, the precursor times are 2.5 - 3 months (listed in Table 1).

To study the moving direction of residual crustal displacements, Chen et al. (2011b) developed a method to calculate the GPS index that is the average of the differences of GPS-azimuth orientations between two stations within a spatially moving area of $80 \times 80 \mathrm{~km}^{2}$. A moving window must cover at least seven GPS stations to remove the effects due to long-term plate movements and short-term noise to retrieve the non-linear and non-stationary crustal deformations. Chen et al. (2011a, b) used the GPS index method to study crustal deformations for $32 M_{L} \geq 5$ earthquakes during 2006 to 2009. Results show that the crustal deformations were re-oriented into a parallel direction a few days before $63 \%(=20 / 32)$ events. Such a parallelism of GPS index becomes random in order when the stress is close to the threshold of faulting. They found that the time period from the presence of random orientation of crustal deformations to earthquake occurrence is positively related to earthquake magnitude. The precursor time is a few days (listed in Ta- ble 1). Chen et al. (2013a) calculated the GPS index before the 4 March $2010 M_{L} 6.4$ Jiashian earthquake. They found that an average of $\sim 60^{\circ}$ and GPS index $=\sim 0.017$ gradually appeared in an area around $\left(22.5^{\circ} \mathrm{N}, 120.7^{\circ} \mathrm{E}\right)$, which is to the south of the mainshock epicenter $\left(22.97^{\circ} \mathrm{N}, 120.71^{\circ} \mathrm{E}\right)$, about 8 days before the mainshock. This phenomenon suggests that the stresses related to the mainshock was gradually disturbed on the crust and thus induced subsurface movements toward the NE direction. The precursor time is 8 days (listed in Table 1).

From the GPS data, Fu et al. (2017b) observed a decrease in extension rate about 4 months before the 31 October $2013 M_{L} 6.4$ Rueisuei earthquake. The precursor time is 4 months (listed in Table 1). Although the magnitude of this event is almost the same as that of the 2010 Jiashian earthquake (Chen et al. 2013a), the precursor time for subsurface deformations is much longer for the former than for the latter. The former occurred in eastern Taiwan, while the latter did in western Taiwan. Hence, different tectonic structures in the two regions might lead to such a difference. Nevertheless, more data are necessary for further studies.

\subsubsection{Variation in $b$-Values}

Lin (2010) estimated the $b$-values of background seismicity and foreshocks before the 4 March $2008 M_{L} 5.2$ Taoyuan earthquake in southern Taiwan. He found that the $b$-value of foreshocks occurred about one month before the mainshock was higher than that of background seismicity because a remarkable decrease in $M_{L}>2.2$ events. The precursor time is one month (listed in Table 1).

From the studies of $b$-values as mentioned above, the plot of the precursor time, $T$, versus earthquake magnitude, $M_{L}$, or the $b$-value anomalies from Chen et al. (1990), Tsai et al. (2004), Wu et al. (2008), and Lin (2010), is shown in Fig. 4. Obviously, $T$ increases with $M_{L}$. This is consistent with the conclusion made by Wang et al. (2016) from worldwide earthquakes. From 45 world-wide earthquakes with $3 \leq$ $M \leq 9$, Wang et al. (2016) inferred a regression equation between $\log (T)(T$ in days $)$ and $M_{\mathrm{s}}$ as: $\log (T)=(2.02 \pm 0.49)+$ $(0.15 \pm 0.07) M_{\mathrm{s}}$. In order to apply this equation in this study, $M_{s}$ must be transferred to $M_{L}$ through $M_{s}=-(0.53 \pm 0.36)+$ $(1.03 \pm 0.06) M_{L}$ that was inferred by Chen et al. (2007) for Taiwan's earthquakes. Hence, we obtain the equation:

$\log (T)=1.94+0.15 M_{L}$

Equation (1) is shown by a thin solid line in Fig. 4. To plot this thin solid line, the value of $T$ has been transferred from 'days' to 'years.' The data point for $M_{L}=5.2$ is blow the line; while others are above the line, thus suggesting that the $b$-value anomalies appeared earlier for the three $M_{L}>6$ Taiwan's events than for world-wide ones. 


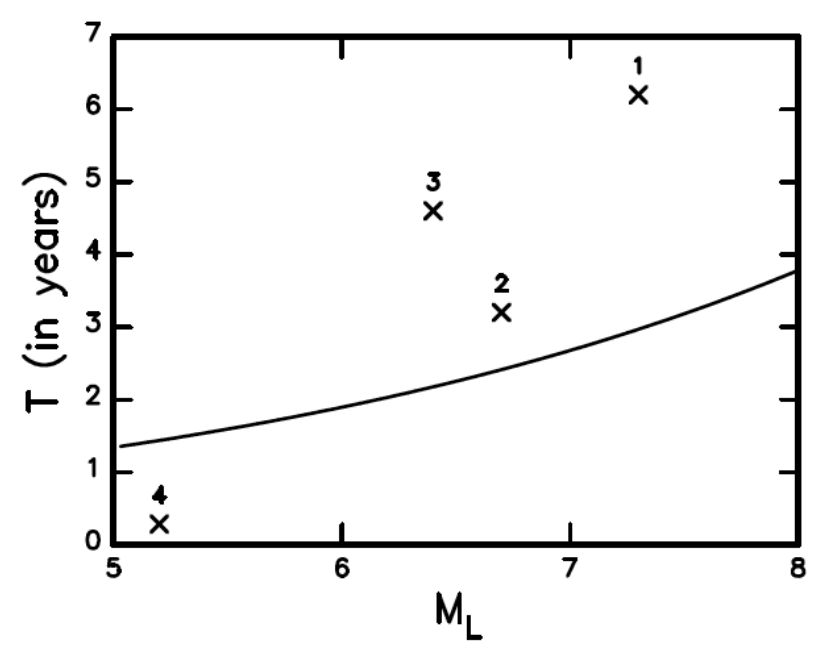

Fig. 4. The plot of $T$ versus $M_{L}$ for the $b$-value anomalies. The thin solid line represents Eq. (1) shown in the text. Numbers: ' 1 ' from Tsai et al. (2006); '2' from Wu et al. (2008); '3' from Chen et al. (1990); and '4' from Lin (2010).

\subsection{3 $Q_{p}$ Changes}

Changes of $P$ - and $S$-wave attenuation (denoted by $Q_{p}$ and $Q_{s}$, respectively) have been long considered as an earthquake precursor (e.g., Gusev and Lemzikov 1985; Sato 1986; Fremont and Poupinet 1987). Wen et al. (2015) measured the temporal variation in $Q_{p}$ of $P$-waves from January 2009 to January 2010. Results show that the $Q_{p}$ began to decrease at all stations about 2 months before the 5 November $2009 M_{L} 6.2$ Ming-Jen earthquake. The precursor time is 2 months (listed in Table 1).

\subsubsection{Groundwater Level Changes}

$\mathrm{Yu}$ and Mitchell (1988) observed clear groundwater level change at a well, which has a depth of $500 \mathrm{~m}$ and is located at the Chingshui River in Ilan, northeastern Taiwan. This abnormal phenomenon appeared about 10 days before the 16 January $1986 M_{L} 6.2$ offshore Ilan earthquake. The precursor time is 10 days (listed in Table 1). In comparison with the 1999 Chi-Chi earthquake, it seems that the precursor time for groundwater well level change increases with earthquake magnitude. Of course, it needs more data to confirm this possible correlation.

\subsubsection{Gas Well Pressure Fluctuation}

The permeability that is formed by pores and/or joints and the pressure gradient in a reservoir may be affected by stress. Production and well-head pressure data from oil and gas wells may useful for the study of changes of local stresses. It is reasonable to expect that oil and gas wells would behave in much the same way as changes of levels and flow rates in water wells before and after earthquakes. Arieh and Merzer (1974) first searched for the possible precursor from the oil well data. Wu (1975) and Wu and Feng (1975) reported that the gas well pressure fluctuations occurred about 9 days before the 18 January $1964 M_{L} 6.3$ Tainan-Chiayi (Paiho) earthquake. The precursor time is 9 days (listed in Table 1).

\subsection{Electromagnetic Precursors}

\subsubsection{Geoelectric Field Anomalies}

Chen and Chen (2016) installed a network (named as the GEMS network) including 22 stations (illustrated by crosses in Fig. 1) in Taiwan to monitor the geoelectric field. They also developed an earthquake-alarm model (called the GEMSTIP model) based on the skewness and kurtosis anomalies of geoelectric field. Using the model, they studied the anomalies of geoelectric field for $M_{L} \geq 5$ earthquakes. Results reveal that the precursor times are 5 - 80 days (with a median value of 60 days) at different stations. A time lag that exists between clusters of anomalies and earthquakes depends on local geological structures and the durations of anomalies. Chen et al. (2017) observed the appearance of anomalies at four stations, i.e., LIOQ, WANL, KAOH, and $\mathrm{CHCH}$, near the epicenter before the 6 February $2016 M_{L}$ 6.6 Meinong earthquake. The precursor times are 20 days at the $\mathrm{CHCH}$ station and 50 days at the $\mathrm{KAOH}$ station. Previous two studies suggest that the precursor time is 5 - 80 days (listed in Table 1).

\subsubsection{Seismo-Geomagnetic Anomalies}

From the analyses of the data recorded by the IESGN, Yen et al. (2004) observed significant fluctuations, with the largest amplitude up to $200 \mathrm{nTs}$, in the differences of total geomagnetic intensity (TGI) between the LY station and the LP station during mid-August (about 1.1 months before the 
1999 Chi-Chi earthquake) to November 1999. The precursor time is $\sim 1.1$ months (listed in Table 1).

From the data recorded by the IESGN during 1988 to 2001, Liu et al. (2006) used the load-unload ratio technique (Zeng et al. 2002) to study the temporal variations in TGI before $M_{L} \geq 5$ earthquakes. First, they computed the diurnal range ratio, DRR, of TGI at a station over that at the LY station. Secondly, they calculated the ratio of monitored number of each DRR to the total monitored number in five different time intervals before and after an earthquake and the average ratio of monitored number of each DRR in the whole 13 years. They took the average ratio as the reference. Finally, they plotted the distributions of the ratio in five different time intervals. Their results show that the distribution of the ratio in the month before the mainshock and that in the month during and after the mainshock clearly departed from the reference one. They assumed that changes of underground conductivities/currents underneath the epicentral area and focal mechanism of a forthcoming mainshock are the main factors in affecting the preseismic TGI. Compared with the results by Yen et al. (2004), the precursor time for TGI anomalies observed by Liu et al. (2006) is $~ 1$ month (listed in Table 1).

Chen et al. (2009) studied the possible geomagnetic anomalies before $181 M_{L} \geq 4$ earthquakes during 2002 to 2005 by applying the singular value decomposition (SVD) technique to analyze the 3-component records through a window of $900 \mathrm{~s}$ for every 5-day period in four years. Results reveal that anomalous geomagnetic fields appeared about 10 days before the earthquakes. Hence, the precursor time is 10 days (listed in Table 1).

\subsubsection{Thermal Infrared Radiation}

The thermal infrared radiation (TIR) or long-wave radiation (LWR) is a short-lived anomaly representing energy emitted from Earth in a form of EM radiation. It passes through the atmosphere and goes into space. The outgoing long-wave radiations (OLR) on the top of atmosphere may be detected by satellites (e.g., Ouzounov et al. 2018a). The OLR is influenced by the near-surface temperature, atmospheric temperatures, humidity of the air, and quantity of clouds. These factors are controlled by the intensity of atmospheric convective activity and depend on latitude and altitude (Ouzounov et al. 2006). Several authors (Ouzounov et al. 2018a; and cited references therein) assumed that TIR may carry the short-lived anomalies caused by earthquakes. TIR anomalies appeared 4 - 14 days before an earthquake and decrease very fast after the event. In addition, TIR anomalies may affect a region of several to tens of thousands square $\mathrm{km}$ around the epicenter with a positive temperature deviation of $2-4^{\circ} \mathrm{C}$ or more. In addition to regional meteorological environments, the spatial distribution and temporal variation of TIR may be also influenced by local geological structures and seismo-tectonics conditions.
From a large dataset of night-time TIR measurements by Geostationary Meteorological Satellite/Visible and Infrared Spin-Scan Radiometer (GMS-5/VISSR), Genzano et al. (2015) identified three significant sequences of TIR anomalies before the 1999 Chi-Chi earthquake and one of them appeared about 14 days before and very close to the epicenter. The precursor time is 14 days (listed in Table 1). Pulinets and Dunajecka (2007) analyzed the transient OLR observed by NASA Aqua/AIRS prior to an $M_{L} 5.6$ (or $M_{s}$ 5.9) earthquake (with $d=15.3 \mathrm{~km}$ ) that occurred offshore southeast Taiwan on 19 February 2009. They obtained the normalized residual on 4 days in the day-time and 1,6, and 9 days in the night-time before the earthquake. Hence, the precursor time is 9 days (listed in Table 1). Pulinets and Ouzounov (2011) analyzed the transient OLR observed by NASA Aqua/AIRS prior to an $M_{L} 6.0$ (or $M_{s} 6.2$ ) earthquake (with $d=27.1 \mathrm{~km}$ ) that occurred offshore southeast Taiwan on 19 May 2004. They measured the static 5-year standard deviation in the time period during May 2003 to December 2007 and the static mean of 18th - 20th of five years from 3 day moving mean samples. Finally, they obtained the normalized residual in the time interval of 18 to 20 May 2004. This led to the appearance of $E_{\text {index }}$ anomaly in this time interval. This suggests that the POEA appeared one day before the earthquake. The parameters $E_{\text {index }}$ and POEA will be explained below. Hence, the precursor time for this earthquake is one day (listed in Table 1).

Fu et al. (2020) proposed a method to detect the variation in OLR from the satellite data. They defined the standardized anomaly $E_{\text {Index }}$ to be the OLR anomaly divided by a standard deviation and considered an anomaly, EA, of $E_{\text {Index }}$ as the preseismic signal. By applying this method to analyze the satellite data for $35 M_{L} \geq 6$ earthquakes during 2009 to 2019, they found that typhoons and focal depths are two significant factors in influencing the variation in $E_{\text {Index }}$. From the plot of the number of precursory $E A s$ versus $M_{L}$, they found that the number only slightly increases with $M_{L}$ because the data points are scattered.

The focal depth is also a significant factor in affecting the variation in $E_{\text {Index }}$. Based on Ustaszewski et al. (2012), Fu et al. (2020) took $d=70 \mathrm{~km}$ as a criteria to distinguish the events: 28 shallow events with $d \leq 70 \mathrm{~km}$ and 7 intermediate-depth ones with $d>70 \mathrm{~km}$. They observed consecutive appearances of EAs of LWR about 2 - 15 days before $77 \%$ of earthquakes and thus they considered this phenomenon as a preseismic OLR $E_{\text {Index }}$ anomaly (POEA). From the figures in Fu et al. (2020), we can see that the spatial distribution of POEA is quite random and the POEA appeared only on several days in either day time or night time before the forthcoming earthquakes. This is similar to the observation by Ouzounov et al. (2018a). Meanwhile, the OLR anomalies vary very much for different earthquakes. In this study, we take the largest value of days before a forthcoming event to be the precursor time. From the four studies, 
the precursor time is $1-25$ days (listed in Table 1 ).

Here, we discuss the focal-depth effect from an alternative viewpoint. Wang et al. (1994) reported that inland earthquakes in Taiwan were located mainly in the depth range $0-12 \mathrm{~km}$. The crust-upper mantle boundary with $v_{p}=$ $7.5 \mathrm{~km} \mathrm{~s}^{-1}$ in the Taiwan region is mainly in the range $35-45$ $\mathrm{km}$ as inferred by several authors (e.g., Rau and Wu 1995; Ma et al. 1996; Kim et al. 2005). Hence, an average depth of $40 \mathrm{~km}$ is taken as a boundary to classify the events: a crustal event with $d \leq 40 \mathrm{~km}$ and an upper-mantle or subductionzone event with $d>40 \mathrm{~km}$. The plot of $T$ versus $M_{L}$ is shown in Fig. 5 where the crustal and upper-mantle (or subductionzone) events listed in Fu et al. (2020) are illustrated by open and solid circles, respectively. In addition, the data points obtained by Genzano et al. (2015), Pulinets and Dunajecka (2007), and Pulinets and Ouzounov (2011) are illustrated by an open square, an open triangle, and an open rhomb, respectively, in Fig. 5. Although the data points are quite scattered, two phenomena may be seen. First, for the events with $d \leq$ $40 \mathrm{~km}$ (denoted by open circles) $T$ slightly increases with $M_{L}$; while for the events with $d>40 \mathrm{~km}$ (denoted by solid circles) $T$ clearly decreases with increasing $M_{L}$. Secondly, $T$ is, on the average, longer for events with $d \leq 40 \mathrm{~km}$ than for those with $d>40 \mathrm{~km}$. However, there are anomalously large values of $T$ for two $M_{L} 6.2$ events with $d>40 \mathrm{~km}$ and small values of $T$ for two $M_{L} 6.3$ events with $d \leq 40 \mathrm{~km}$.

\subsubsection{ULF Emissions}

For the 1999 Chi-Chi earthquake, Akinaga et al. (2001) measured the polarization that is the ratio, $Z / G$, of vertical magnetic field, $Z$, to the horizontal one, $G$, from the records of ultra low frequency (ULF, $3003-000 \mathrm{~Hz}$ ) emissions recorded at the LP station. Results exhibit a significant increase in $Z / G$ about two months before the mainshock. Hence, the precursor time is $\sim 2$ months (listed in Table 1).

\subsubsection{Atmospheric Electric Field Anomalies and Lightning}

Liu et al. (2015) examined lightning activities 30 days before and after 78 inland and 230 offshore $M_{L} \geq 5$ earthquakes during 1993 to 2004. They studied the correlations between lightning activities and the location, depth, and magnitude of earthquakes. Results show that lightning activities appear mainly in the area around the forthcoming earthquake and were significantly enhanced in 1 - 30 days, with the largest values from 17 to 19 days, before the $M_{L} \geq 6$ inland events with $d \leq 20 \mathrm{~km}$. This suggests that preseismic slip of an earthquake with $d>20 \mathrm{~km}$ are unable to generate lightning. Moreover, they mentioned that the area around a mainshock epicenter specified with enhanced lightning activity is proportional to $M_{L}$. The precursor time is $1-30$ days (listed in Table 1).

\subsection{Chemical Anomalies}

\subsubsection{Changes of Geochemical Compositions}

Yang et al. (2006) constructed an automatic gas station (denoted by $\mathrm{CL}$ and illustrated by an open triangle in Fig. 1) near the Chuko fault and the Chiayi fault in southwestern Taiwan to continuously monitor the contents of $\mathrm{CO}_{2}, \mathrm{CH}_{4}, \mathrm{~N}_{2}$, and $\mathrm{H}_{2} \mathrm{O}$. They observed significant anomalies in the $\mathrm{CO}_{2} / \mathrm{CH}_{4}$ ratio about 0.1 - 28.1 days before several $M_{L} \geq 4.0$ earthquakes. The precursor time is $0.1-28.1$ days (listed in Table 1).

Based on Yang et al. (2006), the plot of $T$ versus $M_{L}$ and that of $\log (T)$ versus $M_{L}$ for changes of geochemical components are shown in Figs. 6a and b, respectively. The precursor time for changes of geochemical compositions for the 1999 Chi-Chi earthquake obtained by Song et al. (2005) is 210 days as mentioned before. Since the precursor time is much longer than those obtained by Yang et al. (2006), this datum is not plotted in Fig. 6 to avoid the appearance of a very peculiar and un-balanced distribution of data points. In the figure, an open circle is made for an event with $d \leq 40 \mathrm{~km}$ and $\Delta \leq 40 \mathrm{~km}$ and a solid circle for an event with $d>40 \mathrm{~km}$ or $\Delta>40 \mathrm{~km}$. The data points are quite scattered. For $M_{L}<4.2$, T increases with $M_{L}$, while $M_{L}$ 2 4.2. $T$ more or less decreases with increasing $M_{L}$ and $T$ changes very much with $M_{L}$. A decrease in $T$ with increasing $M_{L}$ does not seem reasonable. For $M_{L}>4.5, T$ varies in a large range 6.5 to 28.5 days. Since the monitoring station is fixed, local geochemical conditions could be relatively stable. Hence, this variation in $T$ could be influenced by other factors, including meteorological changes, different focal mechanisms of earthquakes, etc. This problem should be studied in advance.

\subsubsection{Changes of Radon Concentrations}

Rn concentration changes have been long taken as a significant precursor of earthquakes (e.g., Teng 1980; King 1986). In Taiwan, Liu et al. (1983) first observed the Rn concentrations in soils. From the measures of Rn concentrations at a station near a volcanic area, Liu et al. (1984) found that much gas (mainly $\mathrm{CO}_{2}$ ) with hot water was discharged from the well and a very high Rn concentration appeared in the discharged gas. They assumed that anomalously high $\mathrm{Rn}$ concentration is caused by trapping of gases in the water and under-saturated in water with respect to that in gas. This suggests that hot water is very susceptible to Rn loss. They also claimed that the spatial distribution of events which occurred after the appearance of Rn concentration anomalies is not uniform and skewed in certain directions from the $\mathrm{Rn}$ stations. This seems to suggest that an $\mathrm{Rn}$ station is sensitive to earthquakes that occurred in some directions and insensitive to those in others. Fu et al. (2009) found some anomalies might be caused by surface creeping of faults and 
heavy rainfall. Fu et al. (2017b) considered that the solar tide may influence the semi-diurnal variation in soil-gas. Although most of precursor times of Rn concentrations in Taiwan are shorter than 7 days, there are still numerous values are longer than 7 days. Hence, this issue is placed under short-term prediction.

Liu et al. (1984) measured Rn concentration in geothermal waters and $\mathrm{CO}_{2}$-rich cold spring waters at four stations in northern Taiwan from July 1980 to December 1983. Spike-like Rn anomalies were recorded at three stations for $7 M_{L} \geq 4.6$ offshore Ilan earthquakes. Except one, anomalies appeared about 4 - 51 days before the events with $d<10 \mathrm{~km}$ and $\Delta=14-45 \mathrm{~km}$. The precursor time is $4-51$ days (listed in Table 1).
Rn concentration anomalies were observed at the CL station. Anomalies appeared about $0.49-7.40$ days prior to $15 M_{L} \geq 3.7$ earthquakes with $d=2.1-25 \mathrm{~km}$ and $\Delta=4.8$ - $93 \mathrm{~km}$ (Chyi et al. 2001) and about $0.49-6.82$ days prior to $35 M_{L} \geq 3.7$ events with $d=2.1-32.2 \mathrm{~km}$ and $\Delta=1.5$ $257.5 \mathrm{~km}$ (Chyi et al. 2005). But, there were two particular events. Anomalies appeared 8.36 days before an event with $d=3.0 \mathrm{~km}$ and $\Delta=39.3 \mathrm{~km}$ and 13.0 days before the other with $d=6.7 \mathrm{~km}$ and $\Delta=3.0 \mathrm{~km}$. Yang et al. (2005) observed some spike-like anomalously high radon and thoron concentrations in soil gases. They also obtained a similar soil $\mathrm{Rn}$ spectrum from another station, which was $100 \mathrm{~m}$ away from the CL station. Anomalies occurred 1.3 - 14.2 days before $30 M_{L} \geq 4.5$ events with $d=2.5-88.8 \mathrm{~km}$ and $\Delta=4.9$

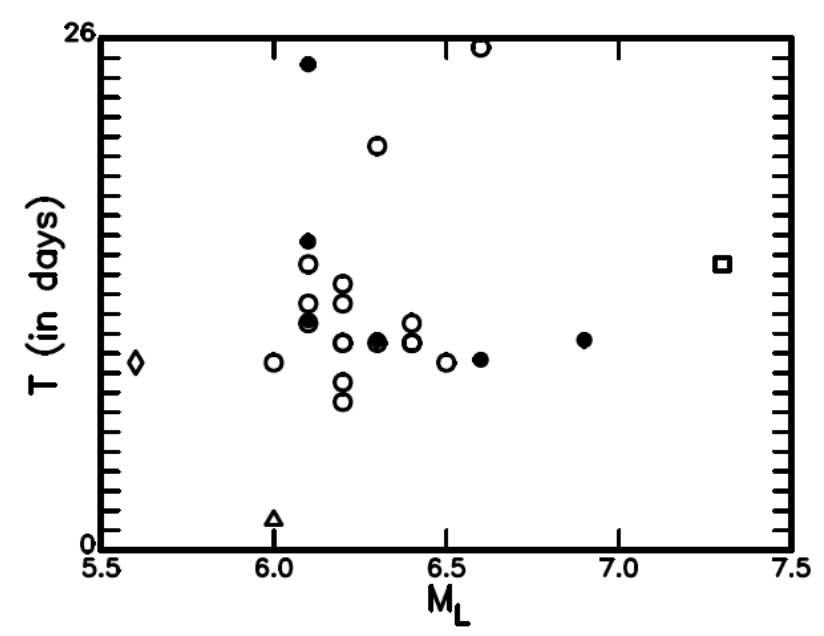

Fig. 5. The plot of $T$ versus $M_{L}$ for thermal infrared emissions. Symbols: 'open circle' for an event with $d \leq 40 \mathrm{~km}$ and 'solid circle' for an events with $d>40 \mathrm{~km}$ from Fu et al. (2020); 'open square' for an event from Genzano et al. (2015); 'open triangle' for an event from Pulinets and Dunajecka (2007); and 'open rhomb' for an event from Pulinets and Ouzounov (2011).
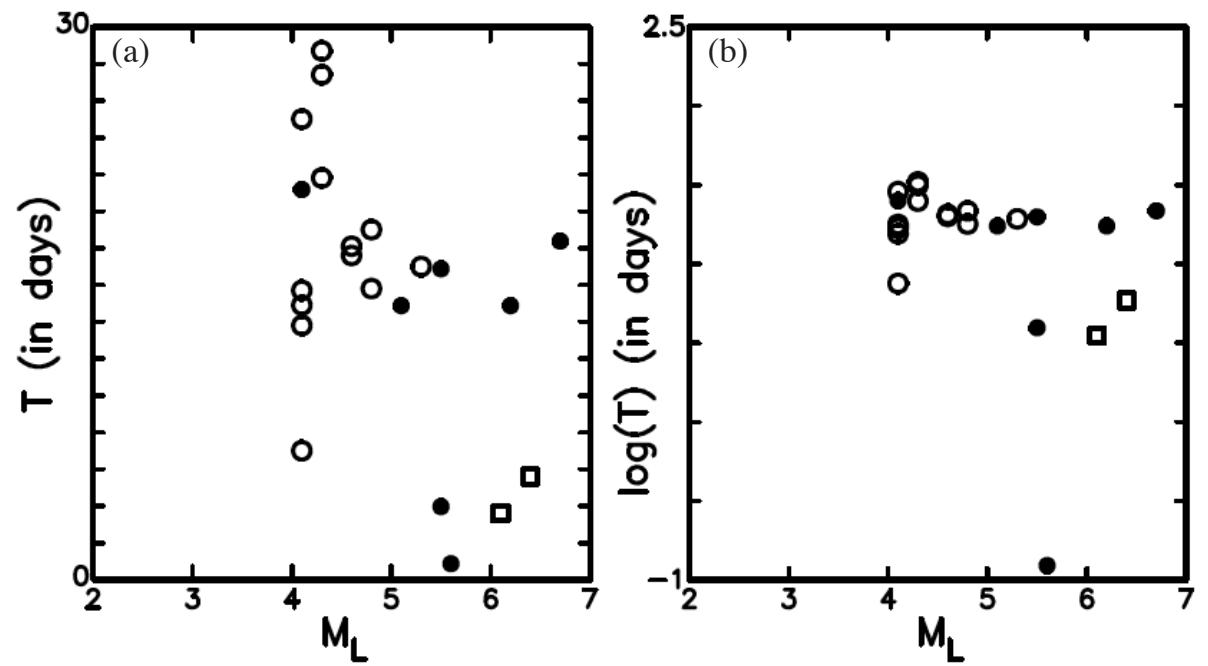

Fig. 6. (a) Plot of $T$ versus $M_{L}$ and (b) plot of $\log (T)$ versus $M_{L}$ for geochemical compositions reported by Yang et al. (2006). Symbols: 'open circle' for an event with $d \leq 40 \mathrm{~km}$ and $\Delta \leq 40 \mathrm{~km}$; 'solid circle' for an event with $d>40 \mathrm{~km}$ from Yang et al. (2006); 'solid square' for an event with $\Delta>$ $40 \mathrm{~km}$ from Yang et al. (2006); and 'open square' for 2 events from Walia et al. (2013). 
- 152.4 km. Fu et al. (2017c) observed a significant increase in soil Rn concentrations at CL, HH, PT, and CS stations (all illustrated by open triangles in Fig. 1) about 14 days before the 6 February $2016 M_{L} 6.6$ Meinong earthquake in southern Taiwan. From the four studies, the precursor time is 0.49 - 14.2 days (listed in Table 1).

Fu et al. (2009) observed Rn concentrations in soil gases across the Chihshang Fault on the LV in eastern Taiwan. They found some high Rn concentration anomalies a few days before local earthquakes. However, they did not provide the magnitude range of events. The precursor time is few days (listed in Table 1). At the DHUG station (illustrated by an open triangle in Fig. 1) on the National Dong-Hua University in eastern Taiwan, Rn concentrations significantly increased about 60 days before the 31 October $2013 M_{L} 6.4$ Rueisuei earthquake and 21 days before the 21 May $2014 M_{L} 5.9$ Fanglin earthquake (Fu et al. 2017b). The two events occurred in the LV area. The precursor times are 21 days and 60 days (listed in Table 1).

$\mathrm{Fu}$ et al. (2017a) studied the spatial distribution and temporal variation of anomalies of $\mathrm{He}, \mathrm{Rn}, \mathrm{N}_{2}, \mathrm{CO}_{2}$, and $\mathrm{CH}_{4}$ in soil gases before 25 events with $M_{L}=3.2-7.0, d=$ $7.9-132.1 \mathrm{~km}$, and $\Delta=7.0-320.1 \mathrm{~km}$ in northern Taiwan. They assumed that spatial anomalies are related to tectonic faults because they found the appearance of high helium and nitrogen concentrations in samples obtained from some specific sites which are associated with the structural setting of the area. They constructed an automatic soil-gas station at Tapingti (denoted by TPT and illustrated by an open triangle in Fig. 1). They found that for 25 earthquakes, anomalously high Rn concentrations recorded at the station appeared about 0.2 - 17.4 days before 13 events, yet not before other 12 events. Among the 12 events, 11 events had $\Delta>58 \mathrm{~km}$ and a small one of $M_{L}=3.5 \mathrm{had} \Delta=7.8 \mathrm{~km}$. This might indicate that Rn concentration anomalies cannot be induced by either distant events or small ones. The precursor time is $0.2-17.4$ days (listed in Table 1). They found that the events with $d<15 \mathrm{~km}$ and $\Delta<30 \mathrm{~km}$ to the west of the station showed mainly strike-slip or normal faulting. They classified those events to Group A. The events with $d>20 \mathrm{~km}$ and $\Delta>45 \mathrm{~km}$ to the east of the station showed mainly thrust faulting. They classified those events to Group B. For the two groups, they also measured the duration, $D_{t}$, of gas anomalies. They found that $T$ linearly increases with $D_{t}$ for the two groups; and both $\log (T)$ and $\log \left(D_{t}\right)$ linearly increase with $M_{L}$ for Group B, yet not for Group A. In addition, they also applied the rock-dilatancy model to interpret the Rn concentration changes.

At the TPT station, Fu et al. (2019) observed anomalous Rn concentrations before 20 of $37 M_{L}=2.3-6.7$ events that happened during 1 July 2014 to 1 June 2015 . The magnitudes of the 15 events are $M_{L}=2.7-6.7$. The authors divided 37 events in study into two groups: $27 M_{L} \geq 5.0$ events for the first group and $10 M_{L} \leq 4.0$ events for the second one. For the first group, expect for one with $M_{L}=5.1$ and $\Delta=37.0 \mathrm{~km}$, anomalies were not observed for the events with $\Delta>55.0 \mathrm{~km}$. This seems to suggest that for the study area, $\Delta=55.0 \mathrm{~km}$ may be an upper bound for the generation of anomalies due to preseimic slip. For the second group, anomalies appeared only before 3 events: 1 day before an event with $M_{L}=3.5, d=10.0 \mathrm{~km}$, and $\Delta=64.0 \mathrm{~km} ; 3$ days before an event with $M_{L}=2.3, d=6.2 \mathrm{~km}$, and $\Delta=71.0 \mathrm{~km}$; and 4 days before an event with $M_{L}=2.9, d=6.0 \mathrm{~km}$, and $\Delta=70.0 \mathrm{~km}$. Consequently, the precursor time is $T=1-23$ days (listed in Table 1).

Kuo et al. (2006a, b, 2010) measured the Rn concentrations at the D1 station (illustrated by an open triangle in Fig. 1) at Antung before three events as mentioned in subsection 4.4.1. They found that $\mathrm{Rn}$ concentrations decreased from background levels of $791 \pm 46,762 \pm 57$, and $735 \pm$ $48 \mathrm{pCi} / \mathrm{L}$ to the minima of $326 \pm 9,371 \pm 9$, and $480 \pm 43$ $\mathrm{pCi} / \mathrm{L}$ about 3, 2.5, and 2.5 months, before the 2003, 2006, and 2008 events, respectively. Kuo et al. $(2017,2018,2019)$ measured the Rn concentrations recorded at the P1 station (illustrated by an open triangle in Fig. 1) at Peiho before five earthquakes, i.e., the 4 March $2010 M_{L} 6.4\left(M_{w} 6.3\right)$ Jiasian earthquake with $d=22.6 \mathrm{~km}$ and $\Delta=46 \mathrm{~km}, 12$ July 2011 $M_{L} 5.3\left(M_{w} 5.0\right)$ Chimei earthquake with $d=31.2 \mathrm{~km}$ and $\Delta=47 \mathrm{~km}, 27$ March $2013 M_{L} 6.2\left(M_{w} 6.0\right)$ Jenan earthquake with $d=19.4 \mathrm{~km}$ and $\Delta=87 \mathrm{~km}, 2$ June $2013 M_{L} 6.5$ $\left(M_{w} 6.3\right)$ Yuchi (written as 'Fishpond' by Kuo and his coauthors) earthquake with $d=31.5 \mathrm{~km}$ and $\Delta=78 \mathrm{~km}$, and 5 February $2016 M_{L} 6.4\left(M_{w} 6.4\right)$ Meinong earthquake with $d=16.7 \mathrm{~km}$ and $\Delta=45 \mathrm{~km}$. They found that Rn concentrations decreased from background levels of $144 \pm 7,752 \pm$ $24,134 \pm 5,137 \pm 8$, and $137 \pm 8 \mathrm{pCi} / \mathrm{L}$ to minima of $104 \pm$ $8,447 \pm 18,85 \pm 4,97 \pm 9$, and $97 \pm 9 \mathrm{pCi} / \mathrm{L}$ about 80,54 , 104, 171, and 54 days before the 2010 Jiasian, 2011 Chimei, 2013 Jenai, 2013 Yuchi, and 2016 Meinong earthquakes, respectively. Hence, the precursor times obtained by Kuo and his co-authors are 54 - 171 days (listed in Table 1). They also found that the $\mathrm{Rn}$ concentration decreased and the aseismic crustal strain increased before the seven thrust-faulting events. Kuo et al. (2006a, 2017) applied the radon-volatilization model and the rock-dilatancy model to interpret the decrease in $\mathrm{Rn}$ concentrations together with increasing strain before an event.

Based on the data of 111 events obtained by Liu et al. (1984), Chyi et al. (2001, 2005), Yang et al. (2005), Fu et al. (2017a, b, c, 2019), and Kuo et al. (2006a, 2010, 2017, 2018, 2019), the plot of $T$ versus $M_{L}$ and that of $\log (T)$ versus $M_{L}$ are shown, respectively, in Figs. 7a and b. Since the data points are quite scattered, the correlation between the two parameters is very weak. Nevertheless, we may still see two phenomena: First, $T$ more or less increases with $M_{L}$. Secondly, $T$ is, on the average, longer for the events with $d \leq 40 \mathrm{~km}$ and $\Delta \leq 40 \mathrm{~km}$ than for those with $d>40 \mathrm{~km}$ or $\Delta>40 \mathrm{~km}$.

The plots of $T$ versus $M_{L}$ and $\log (T)$ versus $M_{L}$ for 

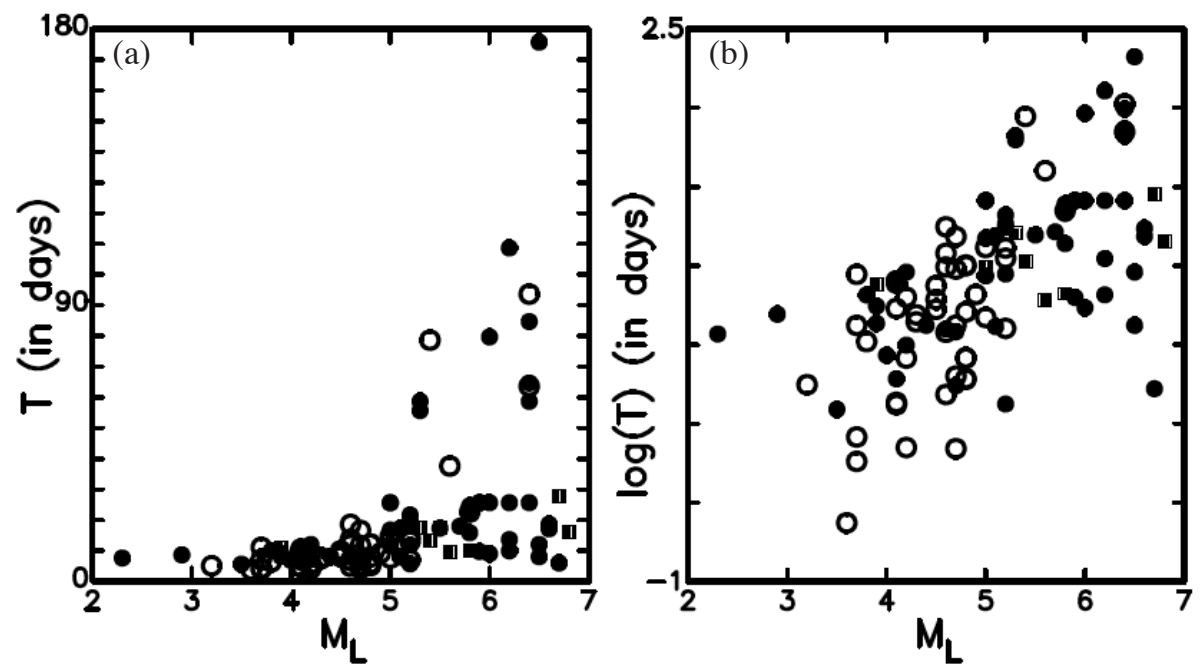

Fig. 7. (a) Plot of $T$ versus $M_{L}$ and (b) plot of $\log (T)$ versus $M_{L}$ for Rn concentration anomalies obtained by several groups of authors (Chyi et al. 2001, 2005; Kuo et al. 2006a, 2010, 2017, 2018, 2019; Yang et al. 2006; Fu et al. 2009, 2017a, b, c, 2019). Symbols: 'open circle' for an event with $d \leq 40 \mathrm{~km}$ and $\Delta \leq 40 \mathrm{~km}$; 'solid circle' for an event with $d>40 \mathrm{~km}$; and 'solid square' for an event with $\Delta>40 \mathrm{~km}$.

the events with $d \leq 40 \mathrm{~km}$ and $\Delta \leq 40 \mathrm{~km}$ are displayed in Figs. 8a and $\mathrm{b}$, respectively, and those for the events with $d>40 \mathrm{~km}$ or $\Delta>40 \mathrm{~km}$ are shown in Figs. 9a and b, respectively. Obviously, Figs. 8 and 9 show better correlations between $T$ and $M_{L}$ than Fig. 7. For the data points in the two figures, the regression equations of $\log (T)$ versus $M_{L}$ are inferred and the results are

$\log (T)=(-2.05 \pm 0.40)+(0.58 \pm 0.01) M_{L}$

for the events with $d \leq 40 \mathrm{~km}$ and $\Delta \leq 40 \mathrm{~km}$ and

$\log (T)=(-0.40 \pm 0.42)+(0.26 \pm 0.01) M_{L}$

for those with $d>40 \mathrm{~km}$ or $\Delta>40 \mathrm{~km}$. Equations (2) and (3) are displayed with thin solid lines in Figs. 8 and 9, respectively. The standard error is slightly smaller for Fig. 8 than for Fig. 9, thus suggesting the degree of scattering of data points is slightly lower and that of fitness of the thin solid line to the data points is slightly better in Fig. 8 than in Fig. 9. Meanwhile, the degree of fitness of the thin solid line to the data points is better in Fig. 8 than in Fig. 9 because the thin solid line covers a wider range of $T$ in the same range of $M_{L}$ for the former than for the latter. This seems to suggest that the precursor times of $\mathrm{Rn}$ concentration anomalies are more reliable for the events with $d \leq 40 \mathrm{~km}$ and $\Delta \leq 40 \mathrm{~km}$ than for those with $d>40 \mathrm{~km}$ or $\Delta>40 \mathrm{~km}$.

\subsubsection{Changes of $\gamma$-Ray Emissions}

The gamma-ray (written as $\gamma$-ray hereafter) emission is mainly produced from the radioactive decay of $\mathrm{Rn}$ or from thunderstorms (e.g., Minnehan 2015). Since fluctuations of $\gamma$-ray records are inversely correlated with atmospheric temperature, this effect must be removed from the recorded data. Four automatically monitoring $\gamma$-ray stations (as illustrated with open diamond symbols in Fig. 1) have been installed in Taiwan (Fu et al. 2015). The four stations are: the YMSG station at the Taiwan Volcano Observatory (TVO) in Mt. Yangming, northern Taiwan the DHUG station at National Dong-Hwa University in Hualien, eastern Taiwan, the CCUG station at National Chung-Cheng University in Chiyi, western Taiwan, and the KTPG station at Kenting National Park in Pingtung, southern Taiwan.

$\mathrm{Fu}$ et al. (2015) observed anomalous $\gamma$-ray emission rate at DHUG station a few days before some earthquakes in eastern Taiwan. In 2014, the $\gamma$-ray emission rate remarkably increased about 7 days before two earthquake swarms: from 20 to 26 March before a swarm (with a maximum magnitude of 4.4) of 26 to 27 March and from 22 April to 1 May before the other (with a maximum magnitude of 5.3) of 3 to 5 May. Furthermore, an anomaly in $\gamma$-ray emission continuously increased ( $\sim \%)$ about 14 days before the 21 May $2014 M_{L} 5.9$ Fanglin earthquake. The precursor time is few to 14 days (listed in Table 1).

At the YMSG station, Fu et al. (2019) observed anomalous $\gamma$-ray emissions before 20 of $37 M_{L}=2.3-6.7$ events that happened during 1 July 2014 to 1 June 2015 . The magnitudes of the 20 events are $M_{L}=2.8-6.7$. The authors divided 37 events in study into two groups: $27 M_{L} \geq 5.0$ events for the first group and $10 M_{L} \leq 4.0$ events for the second one. For the first group, anomalies appeared about 3 - 20 days before 13 events; while for the second group, anomalies appeared about 2 - 7 days before 7 events. Consequently, the 

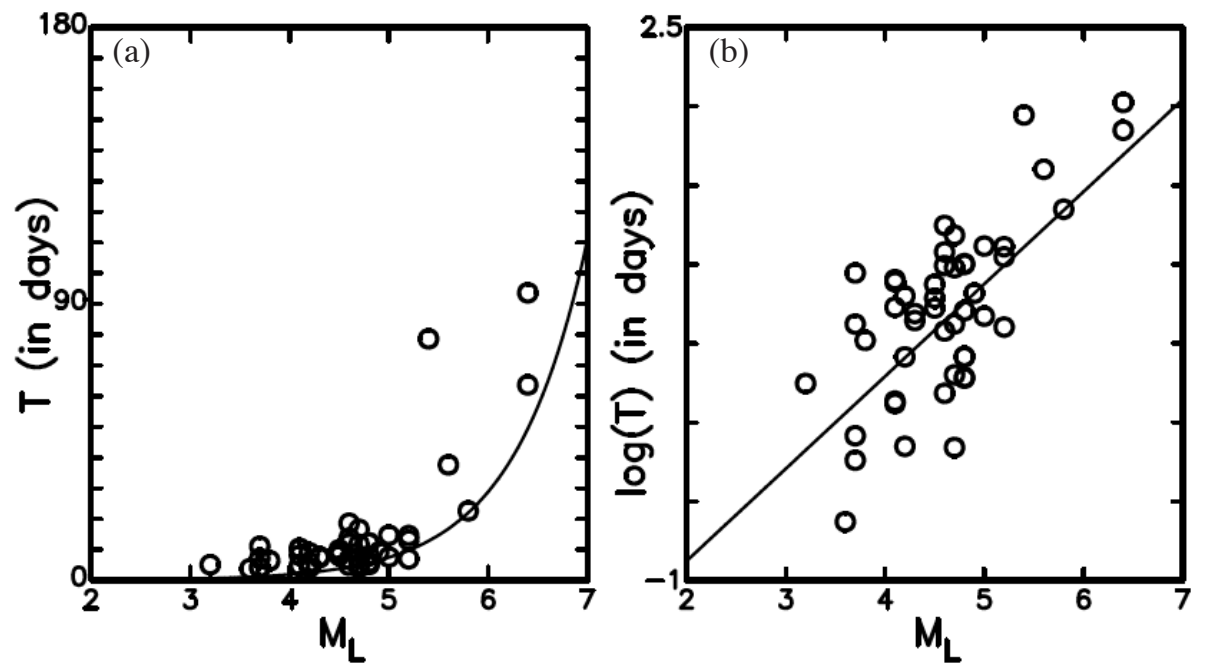

Fig. 8. (a) Plot of $T$ versus $M_{L}$ and (b) plot of $\log (T)$ versus $M_{L}$ for Rn concentrations from Fig. 7 for events with $d \leq 40 \mathrm{~km}$ and $\Delta \leq 40 \mathrm{~km}$. The thin solid line represents Eq. (2) in the text.
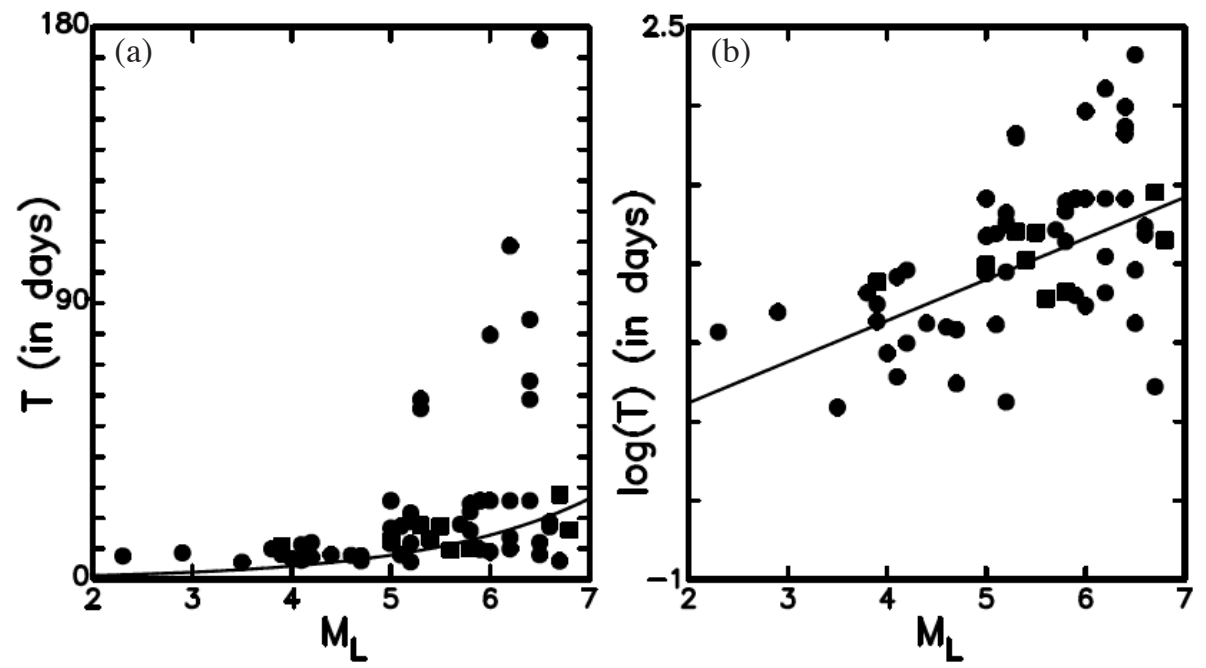

Fig. 9. (a) Plot of $T$ versus $M_{L}$ and (b) plot of $\log (T)$ versus $M_{L}$ for Rn concentration anomalies from Fig. 7. The thin solid line represents Eq. (3) in the text. Symbols: 'solid circle' for an event with $d>40 \mathrm{~km}$; and 'solid square' for an event with $\Delta>40 \mathrm{~km}$.

precursor time is $T=2-20$ days (listed in Table 1 ).

Although the two types of precursors were detected at two different stations by Fu et al. (2015, 2019), it is significant to explore the possible correlation between them. Let $T_{g r}$ and $T_{R n}$ be the precursor time of $\gamma$-ray emission anomaly and that of Rn concentration anomaly, respectively. Based on the data of one event from Fu et al. (2015) and 7 events from Fu et al. (2019), Fig. 10 includes two plots: (a) for $T_{g r}$ versus $T_{R n}$, and (b) for $T_{R n}-T_{g r}$ versus $T_{R n}$. Figure 10a shows an increase in $T_{g r}$ with $T_{R n}$. Although the data points in Fig. 10b are somewhat scattered, it still shows an increase in $T_{R n}-T_{g r}$ with $T_{R n}$. Figure 10 reveals that the $\gamma$-ray emission is associated with the radioactive decay of $\mathrm{Rn}$ as expected theoretically. Figure 11 shows two plots: (a) for $T_{g r}$ (in a solid square) and $T_{R n}$ (in a solid circle) versus $M_{L}$, and (b) for $T_{R n}{ }^{-} T_{g r}$ versus $M_{L}$. Although the data points are somewhat scattered, the correlation between the two parameters may be recognized. Figure 11a shows increases in both $T_{R n}$ and $T_{g r}$ with $M_{L}$, thus suggesting that the larger the forthcoming earthquake is, the earlier the occurrence times of the two precursors are. Figure $11 \mathrm{~b}$ shows an increase in $T_{R n}-T_{g r}$ with $M_{L}$. From both Figs. $10 \mathrm{~b}$ and $11 \mathrm{~b}$, we can see that when the occurrence time of anomalous $\gamma$-ray emissions after the $\mathrm{Rn}$ concentration anomalies is longer, the forthcoming earthquake is bigger and its occurrence time, i.e., $T_{R n}$, is longer. This may provide earthquake scientists a possible opportunity of predicting an earthquake. Co-sited observations of Rn concentrations and $\gamma$-ray emissions should be useful. 

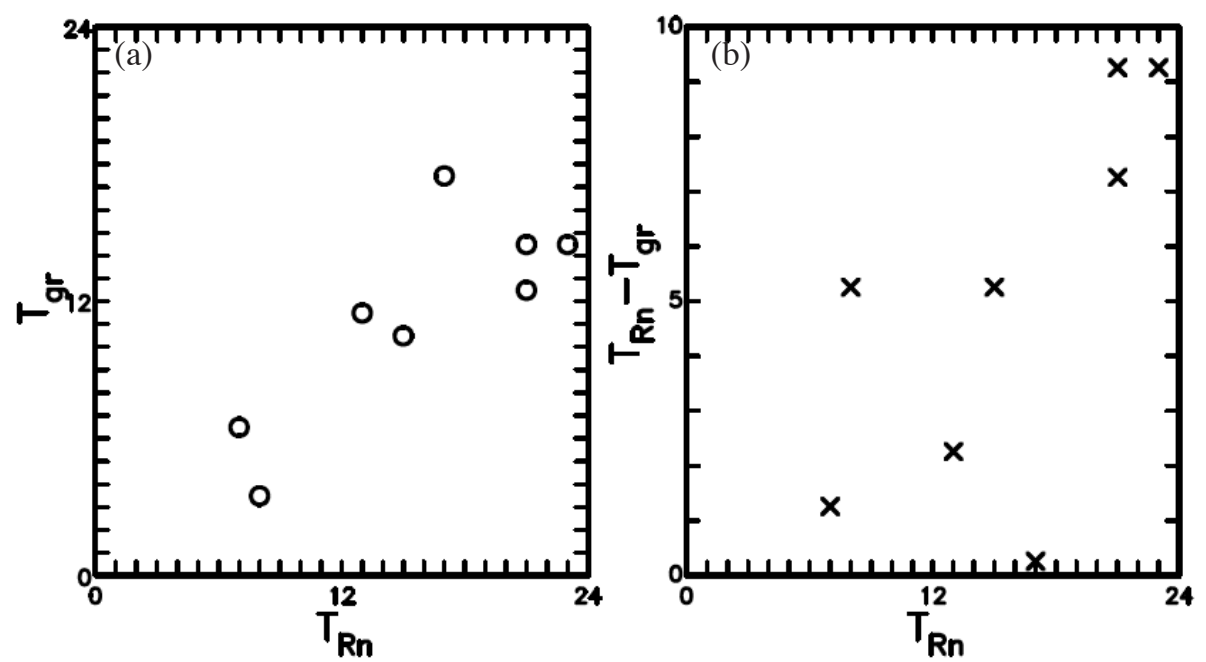

Fig. 10. (a) for $T_{g r}$ (precursor time for $\gamma$-ray emission anomaly) versus $T_{R n}$ (precursor time for Rn concentration anomaly), and (b) for $T_{R n}-T_{g r}$ versus $T_{R n}$ from Fu et al. $(2015,2019)$.
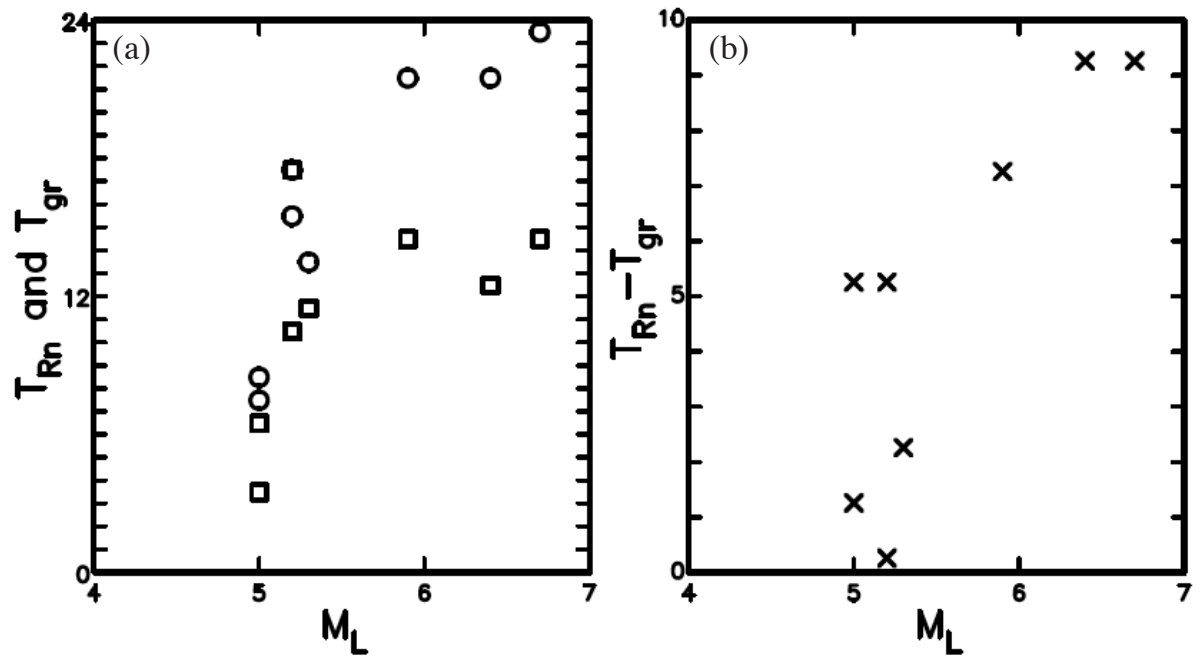

Fig. 11. (a) for $T_{R n}$ and $T_{g r}$ versus $M_{L}$, and (b) for $T_{R n}-T_{g \mathrm{r}}$ versus $M_{L}$ from Fu et al. $(2015,2019)$. Symbols: 'open square' for $T_{R n}$ and 'open circle' for $T_{g r}$ in (a) and 'cross' for $T_{R n}-T_{g r}$ in (b).

\section{IMMINENT PREDICTION}

\subsection{Mechanical Precursor}

\subsubsection{Foreshocks}

In addition to forerunner as mentioned above, Chen and Wang (1984) and Chen et al. (1990) also observed foreshocks that occurred within a small area about 4 days before the 20 May $1983 M_{L} 6.4$ Taipingshan earthquake. The $M_{L}$ value of the largest foreshock was 5.5. The mainshock occurred in the southern part of the foreshock area. The precursor time is $\sim 4$ days (listed in Table 1).

Lin (2009) studied foreshock activities of $10 M_{L} \geq 5$ earthquake sequences with $M_{L} \geq 4.0$ felt foreshocks during 1990 to 2004. He stressed that when the largest foreshock and the mainshock have the similar focal mechanism, the former commonly occurred 5 days before and at a distance of $15 \mathrm{~km}$ from the latter. He also addressed that such a kind of felt foreshock often happens at the strongly heterogeneous crust, particularly along the convergent zone between the EP and PSP. The precursor time is 5 days (listed in Table 1).

Lin (2010) studied the foreshock activities of the 4 March $2008 M_{L} 5.2$ Taoyuan earthquake in southern Taiwan. He found that the earthquake was preceded by two groups (A and $\mathrm{B}$ ) of foreshocks that clustered along the major fault plane and dipped to southeast. Group A, consisting of 29 micro-events with $0.6 \leq M_{L} \leq 2.2$, occurred several hours before the mainshock. Group B, including 35 events with the largest one having $M_{L}=4.0$, started about $20 \mathrm{~min}$ utes before the mainshock. The precursor times are from 0.3 to several hours (listed in Table 1). 
Before the $M_{L} 6.2\left(M_{w} 6.3\right)$ Hualien earthquake of 6 February 2018, there were foreshocks with the largest one of $M_{L}=5.8$ or $M_{w}=6.1$ (e.g., Chan et al. 2019). The precursor time is 2 days (listed in Table 1 ).

Here, we consider an alternative precursor time that is measured from the occurrence of the largest foreshock to the mainshock. From the previous four studies (Chen et al. 1990; Lin 2010, 2012; Chan et al. 2019), the plots of $T$ versus $M_{L}$ and $\log (T)$ versus $M_{L}$ for 13 events are displayed in Figs. 12a and b, respectively. Although the data points are somewhat scattered, $T$ somewhat increases with $M_{L}$. In order to explore the correlation between $M_{L}$ of a mainshock (denoted by $M_{L m}$ ) and $M_{L}$ of its largest foreshock (denoted by $M_{L f}$ ), the plot of $M_{L m}$ versus $M_{L f}$ for the 13 events is shown in Fig. 13a. There is a positive correlation between $M_{L m}$ and $M_{L f}$, even though the data points are scattered. This indicates that the bigger the largest foreshock is, the larger the mainshock is. Although the correlation sounds good for earthquake prediction, there is a weak point that foreshocks may not be observed for some earthquakes, for instance the 1999 Chi-Chi earthquake. In order to explore the correlation between the epicentral distance, $\Delta$ (in $\mathrm{km}$ ), from the largest foreshock and the mainshock with $M_{L}$, the plot of $\Delta$ versus $M_{L}$ for the 13 events is shown in Fig. 13b. Clearly, $\Delta$ is shorter than $18 \mathrm{~km}$ for 11 earthquakes and longer than $160 \mathrm{~km}$ or 2 events. Hence, there is not any positive correlation between $\Delta$ and $M_{L}$. Note that for the latter two particular events with $\Delta>160 \mathrm{~km}$, the differences in $M_{L}$ and $T$ between the largest foreshock and the mainshock are small: $\delta M_{L}=0.6$ and $T=0.09$ days for one event with $\Delta=178.5$ $\mathrm{km}$ and $\delta M_{L}=0.8$ and $T=0.39$ days for the other with $\Delta=$ $165.2 \mathrm{~km}$

\subsubsection{Slow-Slip Events}

Slow-slip events may be considered as a precursor of a forthcoming large earthquake (see Nishikawa and Ide 2018; and cited references therein). Based on the surface crustal deformations integrated from broadband velocity seismograms of the CWB, Lin (2012) found significant deviations of the vertical displacement from a normal Earth tidal pattern during 15 to 19 September before the 1999 Chi-Chi earthquake. He assumed that this phenomenon was caused by a series of slow-slip events on the nearly horizontal plane (i.e., the decollement) of the Chelungpu fault at depths of 10 - $12 \mathrm{~km}$. The precursor time for slow slip is $\sim 5$ days (listed in Table 1).

\subsubsection{Infrasound}

Infrasound signals that may be generated by preseismic and coseismic rock fractures are usually considered as a precursors (e.g., Meredith and Atkinson 1983). From the records of an infrasound recording system installed by the
Institute of Acoustics, Chinese Academy of Science at Beijing, PRC, Xia et al. (2011) observed anomalous infrasound signals with a peak amplitude of $1100 \mathrm{mV}$ at 16:00 - 16:40 pm on 18 September that was about 3 days before the ChiChi earthquake. The precursor time for infrasound signal is $\sim 3$ days (listed in Table 1).

\subsubsection{Duration Ratio}

Aki (1985) claimed that changes of coda waves before earthquakes may be considered as a significant precursor. Wang (1988b) estimated the change of coda waves before and after an earthquake from a comparison between the code-wave attenuation between an earthquake and a distant station and that between the event and a nearby station. He defined the duration ratio to be $D R=T_{d s} / T_{n s}$ where $T_{d s}$ and $T_{n s}$ are the total duration times of seismograms of an event recorded at a distant station and a nearby one, respectively. The way to determine the duration of a seismogram is based on the waveform amplitude. Before the 10 May $1983 M_{L}$ 6.4 Taipingshan earthquake, four distant stations and one nearby station of the Taiwan Telemetered Seismographic Network operated by the IES (Wang 1989) had the same gain with $72 \mathrm{~dB}$. From the seismograms recorded at the five stations, Wang (1988b) measured the daily $D R$ values in ten days before the earthquake. Results show that the $D R$ values show increased about 4 days before the earthquake. Hence, the precursor time is 4 days (listed in Table 1).

\subsection{EM Precursors}

\subsubsection{TEC and $f_{o} F_{2}$ Anomalies}

The TEC anomalies of the ionosphere have been considered as an earthquake precursor for a long time (e.g., Pulinets et al. 2018; and cited references therein). Liu et al. (1996) first explored the problem in Taiwan. Liu et al. (2001) first used two methods to study the seismo-ionospheric signatures prior to an earthquake. First, they measured the TEC recorded by a network of the GPS receivers in Taiwan. Secondly, they analyzed the time series of TEC recorded by an ionosonde that is a sweep frequency pulsed radar device located at $\left(25.0^{\circ} \mathrm{N}, 121.1^{\circ} \mathrm{E}\right)$ in Chungli (illustrated with a larger-sized open circle in Fig. 1). The time series obtained from the two methods reveal a similar tendency of temporal variation. Liu et al. (2001, 2004a, b) applied the two methods to study the temporal variation in TEC prior to the 1999 Chi-Chi earthquake. The temporal variation in TEC is schematically displayed in Fig. 14 where the solid line and dotted lines represent the observations and references (previous 15-day median), respectively. Note that this figure is simplified because the fluctuations are not included. From a comparison between the disturbed data and reference ones, they suggested that TEC decreased significantly in the afternoons about 4,3 , and 1 days before the mainshock. 


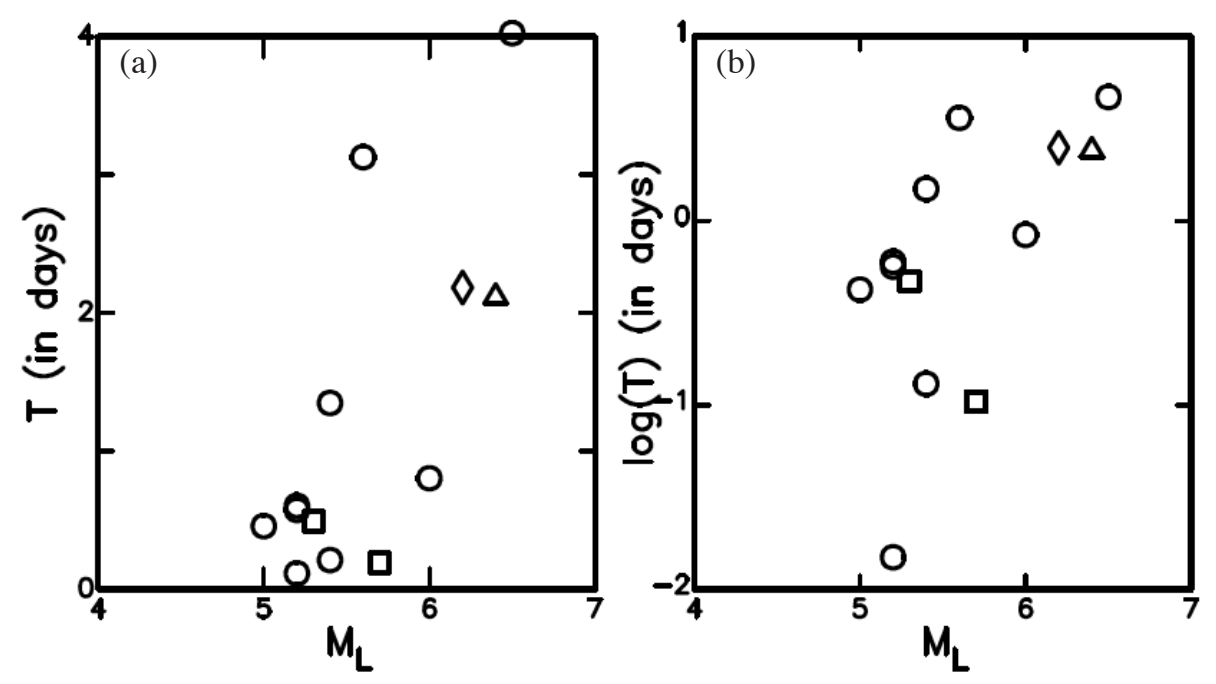

Fig. 12. (a) Plot of $T$ versus $M_{L}$ and (b) plot of $\log (T)$ versus $M_{L}$ for foreshocks. Symbols: 'open circle' for events with $\Delta<20 \mathrm{~km}$ from Lin (2009, 2010), 'open square' for events with $\Delta>160 \mathrm{~km}$ from Lin $(2009,2010)$, 'open tringle' for one event from Chen et al. (1990), and 'open rhomb' for one event from Chan et al. (2019).
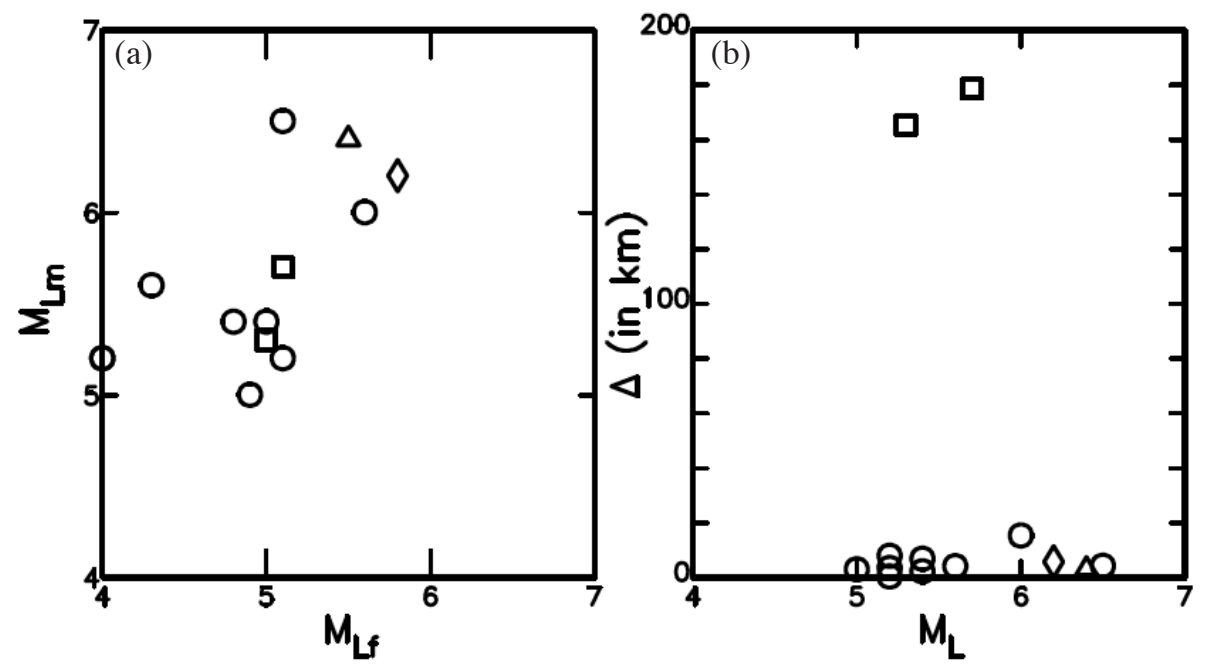

Fig. 13. (a) Plot of $M_{L}$ for mainshocks versus $M_{L}$ for foreshocks, and (b) the epicentral distance (in km), $\Delta$, from the largest foreshock to the mainshock. Symbols: 'open circle' for events with $\Delta<20 \mathrm{~km}$ from Lin $(2009,2010)$, 'open square' for events with $\Delta>160 \mathrm{~km}$ from Lin (2009, 2010), 'open triangle' for one event from Chen et al. (1990), and 'open rhomb' for one event from Chan et al. (2019). 


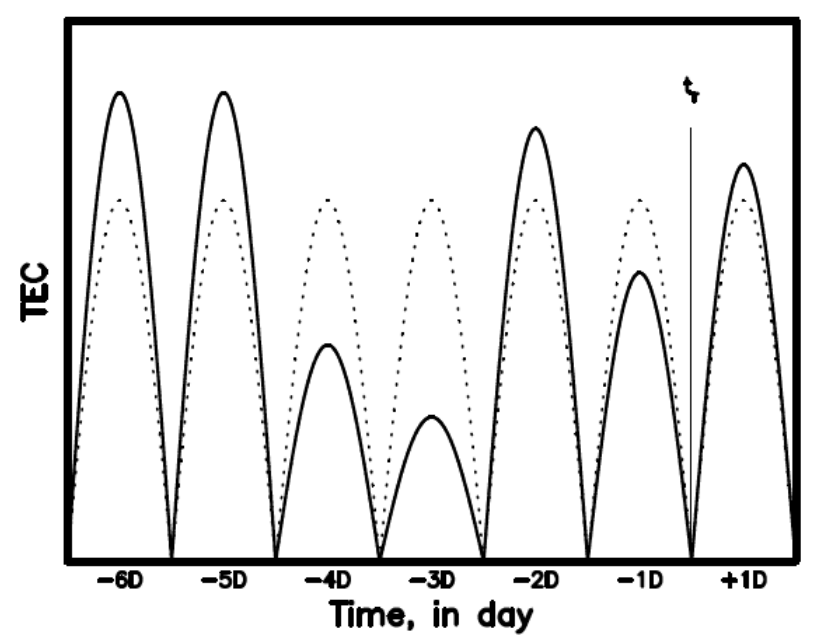

Fig. 14. A simplified figure to show the time variations in TEC anomalies (in a solid line) and the reference data (in a dotted line) from six days before and one day after the mainshock, which occurred at time $t_{r}$, observed by Liu et al. (2001) (modified from Wang 2021b).

The virtual height of the ionosphere is equivalent to the product of one-half the time-of-flight of the transmitted radio wave and the speed of light. The plot of frequency versus virtual height is an ionogram. An ionogram from a vertical sounding displays the frequency-dependent variation of the virtual height of reflection. There are two traces, i.e., Omode and X-mode, on an ionogram. Based on the magnetoionic theory (Budden 1985), the plasma frequency is equal to the vertically reflected $\mathrm{O}$-mode frequency. The highest (or critical) frequency, $f_{o} F_{2}$, on an O-mode trace may be considered as the penetration plasma frequency or the largest density of the ionosphere. The abnormal $f_{o} F_{2}$ is also considered as a precursor. Chuo et al. (2002) analyzed the temporal variation in $f_{o} F_{2}$ recorded at the ChungLi ionosonde station before and after the 1999 Chi-Chi earthquake. Their results are similar to Fig. 14. Results show that the perturbation appeared few days before the event. From Liu et al. (2001, 2004a, b) and Chuo et al. (2002), the precursor times for TEC and $f_{o} F_{2}$ anomalies are 3 - 4 days (listed in Table 1).

Liu et al. (2004b) examined preseismic TEC anomalies for $20 M_{L} \geq 6$ earthquakes in Taiwan from September 1999 to December 2002. Results show that the anomalies appeared about 5 days prior to 16 events (about $80 \%$ of events in study). Liu et al. (2000, 2004a, 2018) examined anomalies of $f_{o} F_{2}$ and TEC for $144 M_{L} \geq 5$ earthquakes during 1997 to 1999 . Results show that remarkable decreases in $f_{o} F_{2}$ and TEC about 4 days before the events. Liu et al. (2008) measured the TEC and $N_{m} F_{2}$, which is the greatest electron density in the ionosphere, before the 26 December $2006 M_{L} 7.0$ offshore Pingtung earthquake doublet. Results show abnormal decreases in TEC and $N_{m} F_{2}$ about 4 days before the earthquake doublets. The precursor time is 3 - 5 days (listed in Table 1). Liu et al. (2008) also reported the appearance of quasi 3-minute fluctuations of pronounced vertical motion in the ionosphere also appeared during the last two days prior to the earthquake doublets. They claimed that this is the first time to observe the pre-earthquake fluctuation signatures in the ionosphere.

From the results obtained by Liu et al. (2001, 2004a, b, 2008, 2018) and Chuo et al. (2002), the plot of $T$ versus $M_{L}$ is shown in Fig. 15. The values of $T$ and $M_{L}$ of four events with $d \leq 40 \mathrm{~km}$ are, respectively, the same as those of four events with $d>40 \mathrm{~km}$. Since Liu and his co-authors did not provide the respective values of $T$ for $M_{L}<6$ events, the related data points are not included in Fig. 15 and thus the plot is only for $M_{L} \geq 6$. Since the data points are quite scattered, and the correlation between the two parameters is very weak.

\subsubsection{Atmospheric Electric Field Anomalies and Lightning}

From the records of cloud-to-ground lightning occurred 15 days before and after the 1999 Chi-Chi earthquake, Tsai et al. (2006) and Liu et al. (2015) reported that the frequency of lightning significantly increased on 17 September 1999 , which was about 4 days before the mainshock, and the lightning occurred mainly near the mainshock epicenter on the southern end of the Chelungpu fault. The precursor time for anomalous lightning is $\sim 4$ days (listed in Table 1).

Based on the corona current measurements, Kamogawa et al. (2004) observed that the atmospheric electric field (AEF) anomalies appeared about 2 and 4 hours before the 31 March $2002 M_{L} 6.8$ Jiashian earthquake. The precursor time for anomalous lightning is about 2 - 4 hours (listed in Table 1).

\subsubsection{Sub-Ionospheric ELF/ULF Emissions}

From the sub-ionospheric ELF/ULF emissions recorded at Nakatsugawa observatory $\left(35.4^{\circ} \mathrm{N}, 137.5^{\circ} \mathrm{E}\right)$ in 


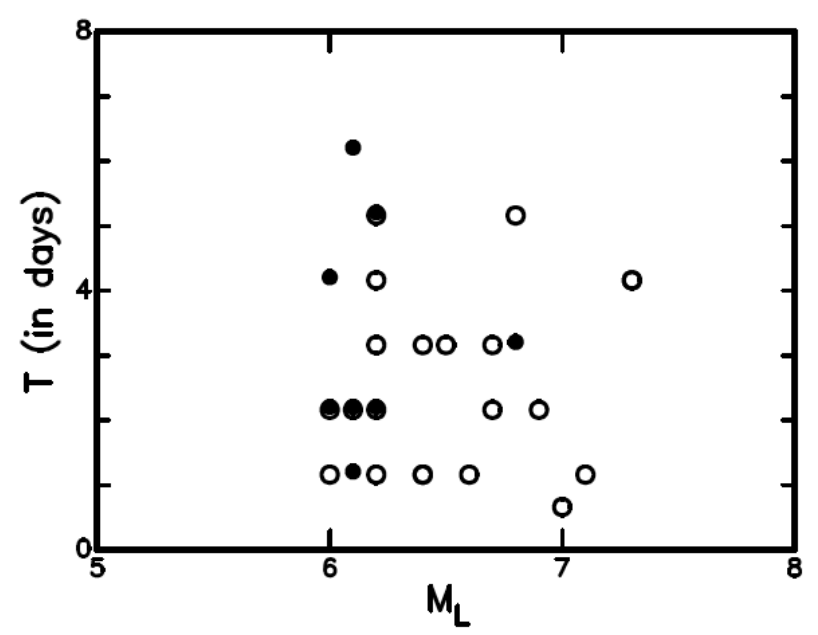

Fig. 15. Plot of $T$ versus $M_{L}$ for TEC anomalies from Liu et al. (2001, 2004a, b, 2008, 2018) and Chuo et al. (2002). Symbols: 'open circle' for events with $d \leq 40 \mathrm{~km}$ and 'solid circle' for events with $d>40 \mathrm{~km}$.

Gifu Prefecture, Japan, during 1 January to 21 September in 1999, Ohta et al. (2001) observed a remarkable change in ELF emissions in 1.5 hours during 20:30 to 22:00 pm (Taiwan Local Time) on 20 September. The phase difference of the ELF emissions indicates that the signals had propagated in the sub-ionospheric waveguide over a long distance and the main direction of the ELF/ULF emissions pointed toward Taiwan. This suggests that the ELF/ULF emissions were produced from the preseismic slip of the 1999 Chi-Chi earthquake. The precursor time is $\sim 4$ hours (listed in Table 1).

Magnetic storms may strongly influence geomagnetic fields. In order to remove the effect by magnetic storms, Wen et al. (2012) isolated amplitude enhancements from the computation of the cross correlations between amplitudes in the earthquake-related frequency band of $0.1-0.01 \mathrm{~Hz}$ and those in the comparable low frequency band of $0.01-0.001$ $\mathrm{Hz}$. They took the computed value as an index of identifying the seismo-geomagnetic anomalies. Results reveal that the index suddenly decreased near the mainshock epicenter a few days before 6 of $9 M_{L} \geq 5$ earthquakes that occurred between September 2010 and March 2011. The precursor time is few days (listed in Table 1).

\subsubsection{Sky and Earthquake Lights}

Chen et al. (2000) reported preseismic sky light (with different colors) and coseismic seismic (green) light before and after the 1999 Chi-Chi earthquake. The 'sky light' might be the earthquake light because it was associated with the earthquake (e.g., Derr 1973, 1986; Lockner et al. 1983; Lockner and Byerlee 1985; and cited references therein). Preseismic sky lights were seen by local people several times from north to south along the Chelungpu fault. The co-seismic earthquake light was seen by local people only once at a site in the northern segment of the fault. The precursor time is few hours (listed in Table 1).

\subsection{Chemical Anomalies}

\subsubsection{Changes of Geochemical Compositions}

Song et al. (2006) measured cation and anion concentrations from water samples at Kuantzeling (denoted by KTL and displayed with a larger-sized open circle in Fig. 1), Chiayi in west-central Taiwan from 15 July 1999 to the end of August 2001. Results reveal that the concentrations of chloride and sulfate ion abruptly increased on 19 September about two days prior to the 1999 Chi-Chi earthquake. The precursor time for anomalous $\mathrm{Cl}^{-1}$ concentration is $\sim 2$ days (listed in Table 1). Since Wang (2021b) wondered if this anomaly was a precursor of the Chi-Chi earthquake or not, this datum is given in Table 1, yet not in Fig. 6 .

Walia et al. (2009) measured soil-gas compositions at stations near the Hsincheng fault, Hsinchu from 1 January 2006 to 14 July 2008 and at those near the Hsinhua fault, Tainan from 30 October 2006 to 14 July 2008. Near the Hsinhua fault, they observed 28 anomalies and 22 of them were associated with 22 of 28 events that occurred in the south or southeastern part of Taiwan. Near the Hsincheng fault, they observed 29 anomalies and 18 of them were related to 18 of 38 events that occurred along Okinawa Trough and Ryukyu Trough. The success ratio is higher for the stations near the Hsinhua fault (79\%) than for those close to the Hsincheng fault $(62 \%)$. For some cases, the precursor time is $1-5$ days. Since Walia et al. (2009) did not provide the values of $T, M_{L}$, $d$, and $\Delta$ for all events in use, their results are given only in Table 1, yet not in Fig. 6. Based on the technique developed by Walia et al. (2009), Walia et al. (2013) observed the appearance of anomalies 3 days before the 4 October $2009 M_{L}$ 6.1 earthquake with $d=29.6 \mathrm{~km}$ in eastern Taiwan and 5 
days before the 4 March $2010 M_{L} 6.4$ earthquake with $d=$ $22.6 \mathrm{~km}$ in southern Taiwan. The precursor time is $3-5$ days (listed in Table 1). Their results are also shown in Fig. 6.

\subsection{Biological Precursors: Anomalous Animal Activities}

Preseismic animal anomalies have been reported for a long time in both historical documents and scientific reports (see Fan 2018; Woith et al. 2018; and cited references therein). Chen et al. (2000) collected the data of anomalous activities for 12 kinds of animals at 28 locations before the 1999 Chi-Chi earthquake. Except for the $28^{\text {th }}$ location at Jiou-Fen-Erl-Shan with an epicentral distance $>10 \mathrm{~km}$, other 27 locations are very close the Chelungpu fault. JiouFen-Erl-Shan is almost in between the Chelungpu fault and Puli. The aberrant behavior of ants occurred as early as 8 10 weeks at a location and 3 days at four other places before the mainshock. The aberrant behavior of cicadas occurred 4 - 6 weeks at a locality before the mainshock. The aberrant behavior of earthwarms, diplopods, and fishes occurred about $1-2$ weeks at some locations before the mainshock. The aberrant behavior of birds occurred $\leq 7$ days at three locations before the event. The roachs abnormally appeared 3 days at a location before the mainshock. The cats abruptly disappeared and turtles abruptly appeared at the same local area $\sim 1$ day before the mainshock. The aberrant behavior of dogs occurred at several locations $<1$ day before the mainshock. The snakes abruptly appeared at a location $\sim 2$ hours before the mainshock. The precursor times for all animals in study are listed in Table 2 where there are three time windows: week, days, and hours.

\section{SUMMARY}

Earthquake prediction has been a long-term debatable problem in earthquake science. In order to resolve the problem, one of the ways is to study the possible precursors of a single earthquake. Since the occurrence of the 1999 Chi-Chi earthquake of 20 September 1999, numerous precursors have been widely observed and studied for many earthquakes in Taiwan. This makes us a chance to explore the debatable problem. In this study, except for the very long-term prediction specified with earthquake recurrence all precursors collected from scientific literature are classified into four categories: (1) mechanical precursors, including seismicity pattern changes, seismic quiescence, crustal deformations, $b$-value anomalies, changes of seismic-wave velocities, hydrological changes, slow-slip events, infrasound, etc.; (2) electromagnetic (EM) precursors, including earthquake lights, thermal infrared radiations or long-wave radiation, geomagnetic fluctuations, sub-ionospheric EM ELF/VHF emissions, cloud-to-ground lightning, anomalies TEC and $f_{o} F_{2}$, etc.; (3) chemical precursors, including changes of geochemical compositions and radon, gamma $(\gamma)$ ray emissions, etc.; and (4) biological precursors, including anomalous behavior of animals.

Based on the time window (or the precursor time, $T$ ), earthquake prediction is defined as follows: long-term prediction (ten years $>T>$ three years); intermediate-term prediction ( $T=$ six months to three years); short-term prediction ( $T=$ eight days to six months); and imminent prediction ( $T \leq$ seven days). The precursor times and ranges of local magnitudes of related events have been compiled and listed in two tables for different time windows. The plots of $T$ versus $M_{L}$ are also made for some precursors, including the $b$-value anomalies, foreshocks, the TIR anomalies, geochemical composition changes, Rn concentration changes, $\gamma$-ray emission anomalies, and TEC anomalies. But, the plot between $T$ and $M_{L}$ cannot be made for others because either the numbers of data are too small or the $T$ values are not provided for respective events by the authors.

For the long-term prediction, only mechanical precursors were observed for the 1999 Chi-Chi earthquake and a few larger-sized events. The substantial results are: the change of stress field before the 1999 Chi-Chi earthquake; the change of seismicity pattern before several earthquakes; the appearance of $b$-value anomalies and changes of $P$-wave travel-time residuals before the Chi-Chi earthquake. The $b$ value anomalies and changes of $P$-wave travel-time residuals may be interpreted by a theoretical model proposed by Wang (2016). The precursor times for three larger-sized earthquakes are longer than those calculated from a $\log (T)$ $M_{w}$ relationship inferred from 45 world-wide events by Wang et al. (2016).

For the intermediate-term prediction, four mechanical precursors, an EM precursor, and a geochemical precursor were observed for the 1999 Chi-Chi earthquake and a few larger-sized events. The substantial results are: the appearance of seismic quiescence before the Chi-Chi earthquake and a positive correlation between the ground water level changes and geochemical composition changes before the 1999 Chi-Chi earthquake. The changes of groundwater levels and geochemical compositions may be interpreted by the temporal variation of stresses in the topmost layer above the source area.

For the short-term and imminent prediction, there are abundant observations of four categories of precursors for the 1999 Chi-Chi earthquake and a few larger-sized events. Hence, the observations and studies of precursors of the two types of prediction are particular important on and directly related to the prediction of earthquakes. I expect that more observations and studies of short-term and imminent precursors should be conducted in the future.

In this study, the plots of $T$ versus $M_{L}$ are made for some short-term and imminent precursors. Of course, such a plot has also been made for the $b$-value anomalies which include the long- and short-term precursors in this study. But, for some precursors the plot between $T$ and $M_{L}$ cannot 
Table 2. The precursory times of anomalies of different animals before the 1999 Chi-Chi earthquake reported by Chen et al. (2000) (after Wang 2021b).

\begin{tabular}{ccccc}
\hline Animals & Weeks & Days & Hours & Time Window \\
\hline Ants & 1 and $8-10$ & 1 and $2-3$ & & Short-term \\
Cicada & $4-6$ & & & Short-term \\
Diplopods & $1-2$ & $1-2$ & & Short-term \\
Earthwarms & $1-2$ & 1 & & Short-term \\
Fishes & $1-2$ & 1 & & Short-term \\
Birds & 1 & $1-2$ & & Imminent \\
Roach & & 3 & & Imminent \\
Dogs & & 1 & 1 and a few & Imminent \\
Cats & & 1 & & Imminent \\
Turtles & & 1 & & Imminent \\
Palm civet-like & & & a few & Imminent \\
Snakes & & & 2 & Imminent \\
\hline
\end{tabular}

be made because either the numbers of the data are too small or the $T$ values were not given for respective events. From the plots of $T$ versus $M_{L}$, we also explore the correlations between $T$ versus $M_{L}$. Results exhibit that there is a positive correlation between $T$ and $M_{L}$ for the $b$-value anomalies, foreshocks, Rn concentration changes, and $\gamma$-ray emission. Meanwhile, the $\log (T)-M_{L}$ relationships for Rn concentration changes may be inferred for both the events with $d \leq 40$ $\mathrm{km}$ and those with $d>40 \mathrm{~km}$. Of course, the degree of positive correlation is better for the events with $d \leq 40 \mathrm{~km}$ than for those with $d>40 \mathrm{~km}$. This result is very significant for a further study of proposing a physical and chemical model for the production of $\mathrm{Rn}$ concentration changes. There is a positive correlation between the precursor time, $T_{R n}$, for Rn concentration changes and the precursor time, $T_{g r}$, for $\gamma$-ray emissions. Meanwhile, the time difference $T_{R n}-T_{g r}$ is positively correlated with $T_{R n}$ and $M_{L}$ of the forthcoming earthquake. Although the data are rare, the results are quite significant. Hence, more studies on this subject should be done further. On the other hand, the data points of $T$ versus $M_{L}$ for thermal infrared emissions, changes of geochemical compositions, and TEC anomalies are quite scattered and thus not any positive correlation can be recognized from each plot. I assume that more studies must be performed to explore the reasons why the correlation between $T$ and $M_{L}$ is weak for the three types of precursors.

In addition, during the 1999 Chi-Chi earthquake the biological precursors (Chen et al. 2000) occurred near the fault in both short-term and imminent time windows. The observations are very interesting even though the number of data is small and the reliability of data is still debated. The report by Chen et al. (2000) is the first formal scientific literature of biological precursors in Taiwan.
Acknowledgements I would like to express my deep thanks to Prof. Chan (NCU), several anonymous reviewers, and Prof. Rau, Editor of Terrestrial, Atmospheric and Oceanic Sciences for their valuable comments and suggestions on my last submitted manuscript and current one. I also thank Prof. Chien-Chih Chen (NCU) for providing me his unpolished localities of geoelectric stations. This study was financially supported by the Central Weather Bureau (Grand No.: MOTC-CWB-110-E-01) and Institute of Earth Sciences, Academia Sinica, TAIWAN.

\section{REFERENCES}

Aki, K., 1985: Theory of earthquake prediction with special reference to monitoring of the quality factor of lithosphere by the coda method. In: Kisslinger, C. and T. Rikitake (Eds.), Practical Approaches to Earthquake Prediction and Warning, Springer, Dordrecht, 219230, doi: 10.1007/978-94-017-2738-9_2. [Link]

Akinaga, Y., M. Hayakawa, J.-Y. Liu, K. Yumoto, and K. Hattori, 2001: A precursory ULF signature for the ChiChi earthquake in Taiwan. Nat. Hazards Earth Syst. Sci., 1, 33-36, doi: 10.5194/nhess-1-33-2001. [Link]

Arieh, E. and A. M. Merzer, 1974: Fluctuations in oil flow before and after earthquakes. Nature, 247, 534-535, doi: 10.1038/247534a0. [Link]

Budden, K. G., 1985: The Propagation of Radio Waves: The Theory of Radio Waves of Low Power in the Ionosphere and Magnetosphere, Cambridge University Press, 669 pp, doi: 10.1017/CBO9780511564321. [Link]

Chan, C.-H., Y.-M. Wu, T.-L. Tseng, T.-L. Lin, and C.-C. Chen, 2012: Spatial and temporal evolution of $b$-values before large earthquakes in Taiwan. Tectonophysics, 
532-535, 215-222, doi: 10.1016/j.tecto.2012.02.004. [Link]

Chan, C.-H., K.-F. Ma, Y.-T. Lee, and Y.-J. Wang, 2019: Rethinking seismic source model of probabilistic hazard assessment in Taiwan after the 2018 Hualien, Taiwan, earthquake sequence. Seismol. Res. Lett., 90, 8896, doi: 10.1785/0220180225. [Link]

Chen, A. T., T. Ouchi, A. Lin, J. Chen, and T. Maruyama, 2000: Phenomena associated with the 1999 Chi-Chi earthquake in Taiwan, possible precursors and after effects. Terr. Atmos. Ocean. Sci., 11, 689-700, doi: 10.3319/TAO.2000.11.3.689(CCE). [Link]

Chen, C.-C., J. B. Rundle, J. R. Holliday, K. Z. Nanjo, D. L. Turcotte, S.-C. Li, and K. F. Tiampo, 2005a: The 1999 Chi-Chi, Taiwan, earthquake as a typical example of seismic activation and quiescence. Geophys. Res. Lett., 32, L22315, doi: 10.1029/2005gl023991. [Link]

Chen, C.-H., J.-Y. Liu, H.-Y. Yen, X. Zeng, and Y.-H. Yeh, 2004a: Changes of geomagnetic total field and occurrences of earthquakes in Taiwan. Terr. Atmos. Ocean. Sci., 15, 361-370, doi: 10.3319/ TAO.2004.15.3.361(EP). [Link]

Chen, C.-H., T. F. Yang, S.-R. Song, T.-K. Liu, and C.-Y. Lee, 2004b: Environmental geochemistry with respect to the fault activities during 2000-2002 in Chiayi-Tainan and Hsinchu-Miaoli Areas, Western Taiwan. Bull. Cent. Geol. Survey, 17, 129-174. (in Chinese)

Chen, C.-H., T. Y. Yang, S.-R. Song, and T.-K. Liu, 2005b: Earthquake chemistry. In: Wang, J.-H., C.-Y. Wang, Q.-C. Sung, T.-C. Shin, S.-B. Yu, C.-F. Shieh, K.-L. Wen, S.-L. Chung, M. Lee, K.-M. Kuo, K.-C. Chang, and S.-L. Chung (Eds.), The 921 Chi-Chi Major Earthquake, Office of Inter-Ministry Science \& Technology Program for Earthquake and Active-fault Research, National Science Council, Taiwan, 548-569. (in Chinese)

Chen, C.-H., J.-Y. Liu, W.-H. Yang, H.-Y. Yen, K. Hattori, C.-R. Lin, and Y.-H. Yeh, 2009: SMART analysis of geomagnetic data observed in Taiwan. Phys. Chem. Earth, 34, 350-359, doi: 10.1016/j.pce.2008.09.002. [Link]

Chen, C.-H., C.-H. Wang, S. Wen, T.-K. Yeh, J.-Y.Liu, and H.-Y. Yen, 2011a: Seismo-crust displacements associated with earthquakes (M>=5) during 2006-2009, Taiwan. J. Natl. Taiwan Museum, 64, 71-82. (in Chinese with English abstract)

Chen, C.-H., T.-K. Yeh, J.-Y. Liu, C.-H. Wang, S. Wen, H.Y. Yen, and S.-H. Chang, 2011b: Surface deformation and seismic rebound: Implications and applications. Surv. Geophys., 32, 291-313, doi: 10.1007/s10712011-9117-3. [Link]

Chen, C.-H., S. Wen, T.-K. Yeh, C.-H. Wang, H.-Y. Yen, J.-Y. Liu, Y. Hobara, and P. Han, 2013a: Observation of surface displacements from GPS analyses before and after the Jiashian earthquake $(M=6.4)$ in Tai- wan. J. Asian Earth Sci., 62, 662-671, doi: 10.1016/j. jseaes.2012.11.016. [Link]

Chen, C.-H., C.-H. Wang, S. Wen, T.-K. Yeh, C.-H. Lin, J.-Y. Liu, H.-Y. Yen, C. Lin, R.-J. Rau, and T.-W. Lin, 2013b: Anomalous frequency characteristics of groundwater level before major earthquakes in Taiwan. Hydrol. Earth Syst. Sci., 17, 1693-1703, doi: 10.5194/ hess-17-1693-2013. [Link]

Chen, C.-H., C.-C. Tang, K.-C. Cheng, C.-H. Wang, S. Wen, C.-H. Lin, Y.-Y. Wen, G. Meng, T.-K. Yeh, J. C. Jan, H.-Y. Yen, and J.-Y. Liu, 2015: Groundwaterstrain coupling before the $1999 M_{\mathrm{w}} 7.6$ Taiwan Chi-Chi earthquake. J. Hydrol., 524, 378-384, doi: 10.1016/j. jhydrol.2015.03.006. [Link]

Chen, H.-J. and C.-C. Chen, 2016: Testing the correlations between anomalies of statistical indexes of the geoelectric system and earthquakes. Nat. Hazards, 84, 877-895, doi: 10.1007/s11069-016-2460-4. [Link]

Chen, H.-J., C.-C. Chen, G. Ouillon, and D. Sornette, 2017: Using geoelectric field skewness and kurtosis to forecast the 2016/2/6, $\mathrm{M}_{\mathrm{L}} 6.6$ Meinong, Taiwan earthquake. Terr. Atmos. Ocean. Sci., 28, 745-761, doi: 10.3319/ TAO.2016.11.01.01. [Link]

Chen, K.-C. and J.-H. Wang, 1984: On the study of May 10, 1983 Taipingshan, Taiwan earthquake sequence. Bull. Inst. Earth Sci. Acad. Sin., 4, 1-27.

Chen, K.-C., J.-H. Wang, and Y.-L. Yeh, 1990: Premonitory phenomena of a moderate Taiwan earthquake. Terr. Atmos. Ocean. Sci., 1, 1-21, doi: 10.3319/ TAO.1990.1.1.1(T). [Link]

Chen, K.-C., W.-G. Huang, and J.-H. Wang, 2007: Relationships among magnitudes and seismic moment of earthquakes in the Taiwan region. Terr. Atmos. Ocean. Sci., 18, 951-973, doi: 10.3319/TAO.2007.18.5.951(T). [Link]

Chuo, Y.-J., J.-Y. Liu, S. A. Pulinets, and Y.-I. Chen, 2002: The ionospheric perturbations prior to the Chi-Chi and Chia-Yi earthquakes. J. Geodyn., 33, 509-517, doi: 10.1016/s0264-3707(02)00011-x. [Link]

Chyi, L.-L., C.-Y. Chou, F. T. Yang, and C.-H. Chen, 2001: Continuous radon measurements in faults and earthquake precursor pattern recognition. West. Pac. Earth Sci., 1, 227-264.

Chyi, L.-L., T. J. Quick, T. F. Yang, and C.-H. Chen, 2005: Soil gas radon spectra and earthquakes. Terr. Atmos. Ocean. Sci., 16, 763-774, doi: 10.3319/ TAO.2005.16.4.763(GIG). [Link]

Cicerone, R. D., J. E. Ebel, and J. Britton, 2009: A systematic compilation of earthquake precursors. Tectonophysics, 476, 371-396, doi: 10.1016/j.tecto.2009.06.008. [Link]

Derr, J. S., 1973: Earthquake lights: A review of observations and present theories. Bull. Seismol. Soc. Am., 63, 2177-2187. 
Derr, J. S., 1986: Rock mechanics: Luminous phenomena and their relationship to rock fracture. Nature, 321, 470-471, doi: 10.1038/321470a0. [Link]

Fan, F., 2018: Can animals predict earthquakes? Bio-sentinels as seismic sensors in communist China and beyond. Stud. Hist.Philos. Sci., 70, 58-69, doi: 10.1016/j. shpsa.2018.05.009. [Link]

Fremont, M. J. and G. Poupinet, 1987: Temporal variation of body-wave attenuation using earthquake doublets. Geophys. J. Int., 90, 503-520, doi: 10.1111/j.1365246x.1987.tb00740.x. [Link]

Fu, C.-C. and L.-C. Lee, 2018: Continuous monitoring of fluid and gas geochemistry for seismic study in Taiwan. In: Ouzounov, D., S. Pulinets, K. Hattori, and P. Taylor (Eds.), Pre-Earthquake Processes: A Multidisciplinary Approach to Earthquake Prediction Studies, Geophysical Monograph Series, Vol. 234, American Geophysical Union, 197-218, doi: 10.1002/9781119156949. ch11. [Link]

Fu, C.-C., T. F. Yang, V. Walia, T.-K. Liu, S.-J. Lin, C.H. Chen, and C.-S. Hou, 2009: Variations of soil-gas composition around the active Chihshang Fault in a plate suture zone, eastern Taiwan. Radiat. Meas., 44, 940-944, doi: 10.1016/j.radmeas.2009.10.095. [Link]

Fu, C.-C., P.-K. Wang, L.-C. Lee, C.-H. Lin, W .-Y. Chang, G. Giuliani, and D. Ouzounov, 2015: Temporal variation of gamma rays as a possible precursor of earthquake in the Longitudinal Valley of eastern Taiwan. J. Asian Earth Sci., 114, 362-372, doi: 10.1016/j. jseaes.2015.04.035. [Link]

Fu, C.-C., T. F. Yang, C.-H. Chen, L.-C. Lee, Y.-M. Wu, T.-K. Liu, V. Walia, A. Kumar, and T.-H. Lai, 2017a: Spatial and temporal anomalies of soil gas in northern Taiwan and its tectonic and seismic implications. J. Asian Earth Sci., 149, 64-77, doi: 10.1016/j. jseaes.2017.02.032. [Link]

Fu, C.-C., T. F. Yang, M.-C. Tsai, L.-C. Lee, T.-K. Liu, V. Walia, C.-H. Chen, W.-Y. Chang, A. Kumar, and T.-H. Lai, 2017b: Exploring the relationship between soil degassing and seismic activity by continuous radon monitoring in the Longitudinal Valley of eastern Taiwan. Chem. Geol., 469, 163-175, doi: 10.1016/j. chemgeo.2016.12.042. [Link]

Fu, C.-C., V. Walia, T. F. Yang, L.-C. Lee, T.-K. Liu, C.-H. Chen, A. Kumar, S.-J. Lin, T.-H. Lai, and K.-L. Wen, 2017c: Preseismic anomalies in soil-gas radon associated with 2016 M 6.6 Meinong earthquake, Southern Taiwan. Terr. Atmos. Ocean. Sci., 28, 787-798, doi: 10.3319/TAO.2017.03.22.01. [Link]

Fu, C.-C., L.-C. Lee, T. F. Yang, C.-H. Lin, C.-H. Chen, V. Walia, T.-K. Liu, D. Ouzounov, G. Giuliani, T.-H. Lai, and P.-K. Wang, 2019: Gamma ray and radon anomalies in Northern Taiwan as a possible preearthquake indicator around the plate boundary. Geofluids, 2019,
1-14, doi: 10.1155/2019/4734513. [Link]

Fu, C.-C., L.-C. Lee, D. Ouzounov, and J.-C. Jan, 2020:

Earth's Outgoing longwave radiation variability prior to $M \geq 6.0$ earthquakes in the Taiwan area during 2009-2019. Front. Earth Sci., 8, 364, doi: 10.3389/ feart.2020.00364. [Link]

Geller, R. J., 1997: Earthquake prediction: A critical review. Geophys. J. Int., 131, 425-450, doi: 10.1111/j.1365246X.1997.tb06588.x. [Link]

Genzano, N., C. Filizzola, R. Paciello, N. Pergola, and V. Tramutoli, 2015: Robust Satellite Techniques (RST) for monitoring earthquake prone areas by satellite TIR observations: The case of 1999 Chi-Chi earthquake (Taiwan). J. Asian Earth Sci., 114, 289-298, doi: 10.1016/j.jseaes.2015.02.010. [Link]

Gokhberg, M. B., V. A. Morgounov, T. Yoshino, and I. Tomizawa, 1982: Experimental measurement of electromagnetic emissions possibly related to earthquakes in Japan. J. Geophys. Res., 87, 7824-7828, doi: 10.1029/ jb087ib09p07824. [Link]

Gusev, A. A. and V. K. Lemzikov, 1985: Properties of scattered elastic waves in the lithosphere of Kamchatka: Parameters and temporal variations. Tectonophysics, 112, 137-153, doi: 10.1016/0040-1951(85)90177-5. [Link]

Hsu, M.-T., 1971: Seismicity of Taiwan and some related problems. Bull. Intern. Inst. Seismol. Earthq. Engin., $\mathbf{8}, 41-160$.

Hsu, Y.-J., L. Rivera, Y.-M. Wu, C.-H. Chang, and H. Kanamori, 2010: Spatial heterogeneity of tectonic stress and friction in the crust: New evidence from earthquake focal mechanisms in Taiwan. Geophys. J. Int., 182, 329-342, doi: 10.1111/j.1365246X.2010.04609.x. [Link]

Kamogawa, M., J.-Y. Liu, H. Fujiwara, Y.-J. Chuo, Y.B. Tsai, K. Hattori, T. Nagao, S. Uyeda, and Y.-H. Ohtsuki, 2004: Atmospheric field variations before the March 31, 2002 M6.8 earthquake in Taiwan. Terr. Atmos. Ocean. Sci., 15, 397-412, doi: 10.3319/ TAO.2004.15.3.397(EP). [Link]

Kawamura, M. and C.-C. Chen, 2013: Precursory change in seismicity revealed by the Epidemic-Type AftershockSequences model: A case study of the 1999 Chi-Chi, Taiwan earthquake. Tectonophysics, 592, 141-149, doi: 10.1016/j.tecto.2013.02.017. [Link]

Kawamura, M., C.-C. Chen, and Y.-M. Wu, 2014: Seismicity change revealed by ETAS, PI, and Z-value methods: A case study of the 2013 Nantou, Taiwan earthquake. Tectonophysics, 634, 139-155, doi: 10.1016/j. tecto.2014.07.028. [Link]

Kim, K.-H., J.-M. Chiu, J. Pujol, K.-C. Chen, B.-S. Huang, Y.-H. Yeh, and P. Shen, 2005: Three-dimensional $V_{P}$ and $V_{S}$ structural models associated with the active subduction and collision tectonics in the Taiwan region. 
Geophys. J. Int., 162, 204-220, doi: 10.1111/j.1365246X.2005.02657.x. [Link]

King, C.-Y., 1986: Gas geochemistry applied to earthquake prediction: An overview. J. Geophys. Res., 91, 1226912281, doi: 10.1029/jb091ib12p12269. [Link]

Kisslinger, C., 1989: Portents and predictions. Nature, 339, 337-338, doi: 10.1038/339337a0. [Link]

Kuo, M. C. T., K. Fan, H. Kuochen, and W. Chen, 2006a: A mechanism for anomalous decline in radon precursory to an earthquake. Ground Water, 44, 642-647, doi: 10.1111/j.1745-6584.2006.00219.x. [Link]

Kuo, T., K. Fan, H. Kuochen, Y. Han, H. Chu, and Y. Lee, 2006b: Anomalous decrease in groundwater radon before the Taiwan M6.8 Chengkung earthquake. $J$. Environ. Radioact., 88, 101-106, doi: 10.1016/j.jenvrad.2006.01.005. [Link]

Kuo, T., C. Lin, G. Chang, K. Fan, W. Cheng, and C. Lewis, 2010: Estimation of aseismic crustal-strain using radon precursors of the 2003 M 6.8, 2006 M 6.1, and 2008 M 5.0 earthquakes in eastern Taiwan. Nat. Hazards, 53, 219-228, doi: 10.1007/s11069-009-9423-y. [Link]

Kuo, T., H. Kuochen, C. Ho, and W. Chen, 2017: A stress condition in aquifer rock for detecting anomalous radon decline precursory to an earthquake. Pure Appl. Geophys., 174, 1291-1301, doi: 10.1007/s00024-0161461-2. [Link]

Kuo, T., W. Chen, and C. Ho, 2018: Anomalous decrease in groundwater radon before $2016 \mathrm{M}_{\mathrm{w}} 6.4$ Meinong earthquake and its application in Taiwan. Appl. Radiat. Isot., 136, 68-72, doi: 10.1016/j.apradiso.2018.02.015. [Link]

Kuo, T., W. Chen, C. Ho, H. Kuochen, and C. Chiang, 2019: In-situ radon volatilization in an undrained fractured aquifer. Proceedings of 44th Workshop on Geothermal Reservoir Engineering, Stanford University, Stanford, California, SGP-TR-214.

Lee, C.-P. and Y.-B. Tsai, 2004: Variations of $P$-wave travel-time residuals before and after the $1999 \mathrm{Chi}-\mathrm{Chi}$, Taiwan, earthquake. Bull. Seismol. Soc. Am., 94, 23482365, doi: 10.1785/0120030213. [Link]

Lin, C.-H., 2009: Foreshock characteristics in Taiwan: Potential earthquake warning. J. Asian Earth Sci., 34, 655-662, doi: 10.1016/j.jseaes.2008.09.006. [Link]

Lin, C.-H., 2010: Temporal $b$-value variations throughout a seismic faulting process: The 2008 Taoyuan earthquake in Taiwan. Terr. Atmos. Ocean. Sci., 21, 229234, doi: 10.3319/TAO.2009.02.09.01(T). [Link]

Lin, C.-H., 2012: The possible observation of slow slip events prior to the occurrence of the 1999 Chi-Chi earthquake. Terr. Atmos. Ocean. Sci., 23, 145-159, doi: 10.3319/TAO.2011.09.23.01(T). [Link]

Liu, J.-Y., H.-F. Tsai, and T.-K. Jung, 1996: Total electron content obtained by using the global positioning system. Terr. Atmos. Ocean. Sci., 7, 107-117, doi:
10.3319/TAO.1996.7.1.107(A). [Link]

Liu, J.-Y., Y.-I. Chen, S. A. Pulinets, Y.-B. Tsai, and Y.J. Chuo, 2000: Seismo-ionospheric signatures prior to $\mathrm{M} \geq 6.0$ Taiwan earthquakes. Geophys. Res. Lett., 27, 3113-3116, doi: 10.1029/2000gl011395. [Link]

Liu, J.-Y., Y.-I. Chen, Y.-J. Chuo, and H. F. Tsai, 2001: Variations of ionospheric total electron content during the Chi-Chi earthquake. Geophys. Res. Lett., 28, 13831386, doi: 10.1029/2000gl012511. [Link]

Liu, J.-Y., Y.-I. Chen, H.-K. Jhuang, and Y.-H. Lin, 2004a: Ionospheric $f_{o} F_{2}$ and TEC anomalous days associated with $\mathrm{M} \geq 5.0$ earthquakes in Taiwan during 1997-1999. Terr. Atmos. Ocean. Sci., 15, 371-383, doi: 10.3319/ TAO.2004.15.3.371(EP). [Link]

Liu, J.-Y., Y.-J. Chuo, S.-J. Shan, Y.-B. Tsai, Y.-I. Chen, S. A. Pulinets, and S.-B. Yu, 2004b: Pre-earthquake ionospheric anomalies registered by continuous GPS TEC measurements. Ann. Geophys., 22, 1585-1593, doi: 10.5194/angeo-22-1585-2004. [Link]

Liu, J.-Y., C.-H. Chen, Y.-I. Chen, H.-Y. Yen, K. Hattori, and K. Yumoto, 2006: Seismo-geomagnetic anomalies and $\mathrm{M} \geq 5.0$ earthquakes observed in Taiwan during 1988-2001. Phys. Chem. Earth, 31, 215-222, doi: 10.1016/j.pce.2006.02.009. [Link]

Liu, J.-Y., S.-W. Chen, Y.-C. Chen, H.-Y. Yen, C.-P. Chang, W.-Y. Chang, L.-C. Tsai, C.-H. Chen, and W.-H. Yang, 2008: Seismo-ionospheric precursors of the 26 December 2006 M 7.0 Pingtung earthquake doublet. Terr. Atmos. Ocean. Sci., 19, 751-759, doi: 10.3319/TAO.2008.19.6.751(PT). [Link]

Liu, J.-Y., Y.-I. Chen, C.-H. Huang, Y.-Y. Ho, and C.-H. Chen, 2015: A statistical study of lightning activities and $\mathrm{M} \geq 5.0$ earthquakes in Taiwan during 1993-2004. Surv. Geophys., 36, 851-859, doi: 10.1007/s10712015-9342-2. [Link]

Liu, J.-Y., K. Hattori, and Y.-I. Chen, 2018: Application of total electron content derived from the global navigation satellite system for detecting earthquake precursors. In: Ouzounov, D., S. Pulinets, K. Hattori, and P. Taylor (Eds.), Pre-Earthquake Processes: A Multidisciplinary Approach to Earthquake Prediction Studies, Geophysical Monograph Series, Vol. 234, American Geophysical Union, 305-317, doi: 10.1002/9781119156949.ch17. [Link]

Liu, K.-K., T.-F. Yui, Y.-H. Yeh, Y.-B. Tsai, and T.-L. Teng, 1984: Variations of radon content in groundwaters and possible correlation with seismic activities in northern Taiwan. Pure Appl. Geophys., 122, 231-244, doi: 10.1007/bf00874596. [Link]

Liu, S.-H., K.-H. Sun, S.-H. Huang, and P.-S. Wen, 1983: A sensitive method for radon measurement. Nucl. Sci., 20, 189-196. (in Chinese)

Lockner, D. A. and J. D. Byerlee, 1985: Complex resistivity of fault gouge and its significance for earthquake lights 
and induced polarization. Geophys. Res. Lett., 12, 211214, doi: 10.1029/g1012i004p00211. [Link]

Lockner, D. A., M. J. S. Johnston, and J. D. Byerlee, 1983: A mechanism to explain the generation of earthquake lights. Nature, 302, 28-33, doi: 10.1038/302028a0. [Link]

Ma, K.-F., J.-H. Wang, and D. Zhao, 1996: Three-dimensional seismic velocity structure of the crust and uppermost mantle beneath Taiwan. J. Phys. Earth, 44, 85-105, doi: 10.4294/jpe1952.44.85. [Link]

Ma, K.-F., C.-T. Lee, Y.-B. Tsai, T.-C. Shin, and J. Mori, 1999: The Chi-Chi, Taiwan earthquake: Large surface displacements on an inland thrust fault. Eos, Trans. $A G U, \mathbf{8 0}, 605-611$, doi: 10.1029/99eo00405. [Link]

Meredith, P. G. and B. K. Atkinson, 1983: Stress corrosion and acoustic emission during tensile crack propagation in Whin Sill dolerite and other basic rocks. Geophys. J. Int., 75, 1-21, doi: 10.1111/j.1365-246x.1983. tb01911.x. [Link]

Meyer, S. L., 1975: Data Analysis for Scientists and Engineers, John Wiley \& Sons, New York, 513 pp.

Minnehan, C., 2015: Newly discovered properties of elusive gamma ray flashes. Eos, 96, doi: 10.1029/2015EO032431. [Link]

Miyamura, S., 1985: The Hsinchu-Taichung, Taiwan, earthquake of April 20, 1935. Proc. Seminar Commemorating the 50th Anniversay of the Great Hsinchu-Taichung Earthquake 1935, 18-44.

Mogi, K., 1981: Seismicity in western Japan and longterm earthquake forecasting. In: Simpson, D. W. and P. G. Richards (Eds.), Earthquake Prediction: An International Review, Maurice Ewing Series, Volume 4, American Geophysical Union, Washington, D.C., USA, 43-51, doi: 10.1029/ME004p0043. [Link]

Molchanov, O. A. and M. Hayakawa, 1995: Generation of ULF electromagnetic emissions by microfracturing. Geophys. Res. Lett., 22, 3091-3094, doi: 10.1029/95gl00781. [Link]

Nishikawa, T. and S. Ide, 2018: Recurring slow slip events and earthquake nucleation in the source region of the $M 7$ Ibaraki-Oki earthquakes revealed by earthquake swarm and foreshock activity. J. Geophys. Res., 123, 7950-7968, doi: 10.1029/2018JB015642. [Link]

Ohta, K., K. Umeda, N. Watanabe, and M. Hayakawa, 2001: ULF/ELF emissions observed in Japan, possibly associated with the Chi-Chi earthquake in Taiwan. Nat. Hazards Earth Syst. Sci., 1, 37-42, doi: 10.5194/ nhess-1-37-2001. [Link]

Ouzounov, D., N. Bryant, T. Logan, S. Pulinets, and P. Taylor, 2006: Satellite thermal IR phenomena associated with some of the major earthquakes in 19992003. Phys. Chem. Earth, 31, 154-163, doi: 10.1016/j. pce.2006.02.036. [Link]

Ouzounov, D., S. Pulinets, K. Hattori, and P. Taylor, 2018a:
Pre-Earthquake Processes: A Multidisciplinary Approach to Earthquake Prediction Studies, Geophysical Monograph Series, Vol. 234, American Geophysical Union, 384 pp, doi: 10.1002/9781119156949. [Link]

Ouzounov, D., S. Pulinets, M. C. Kafatos, and P. Taylor, 2018b: Thermal radiation anomalies associated with major earthquakes. In: Ouzounov, D., S. Pulinets, K. Hattori, and P. Taylor (Eds.), Pre-Earthquake Processes: A Multidisciplinary Approach to Earthquake Prediction Studies, Geophysical Monograph Series, Vol. 234, American Geophysical Union, 259-274, doi: 10.1002/9781119156949.ch15. [Link]

Paudel, S. R., S. P. Banjara, A. Wagle, and F. T. Freund, 2018: Earthquake chemical precursors in groundwater: A review. J. Seismol., 22, 1293-1314, doi: 10.1007/ s10950-018-9739-8. [Link]

Pulinets, S. and D. Ouzounov, 2011: Lithosphere-Atmosphere-Ionosphere Coupling (LAIC) model - An unified concept for earthquake precursors validation. J. Asian Earth Sci., 41, 371-382, doi: 10.1016/j. jseaes.2010.03.005. [Link]

Pulinets, S., D. Ouzounov, A. Karelin, and D. Davidenko, 2018: Lithosphere-Atmosphere-Ionosphere-Magnetosphere Coupling-A Concept for Pre-Earthquake Signals Generation. In: Ouzounov, D., S. Pulinets, K. Hattori, and P. Taylor (Eds.), Pre-Earthquake Processes: A Multidisciplinary Approach to Earthquake Prediction Studies, Geophysical Monograph Series, Vol. 234, American Geophysical Union, 77-98, doi: 10.1002/9781119156949.ch6. [Link]

Pulinets, S. A. and M. A. Dunajecka, 2007: Specific variations of air temperature and relative humidity around the time of Michoacan earthquake M8.1 Sept. 19, 1985 as a possible indicator of interaction between tectonic plates. Tectonophysics, 431, 221-230, doi: 10.1016/j. tecto.2006.05.044. [Link]

Ran, Y.-K., W.-S. Chen, X.-W. Xu, L.-C. Chen, H. Wang, C.-C. Yang, and S.-P. Dong, 2013: Paleoseismic events and recurrence interval along the Beichuan-Yingxiu fault of Longmenshan fault zone, Yingxiu, Sichuan, China. Tectonophysics, 584, 81-90, doi: 10.1016/j. tecto.2012.07.013. [Link]

Rau, R.-J. and F.T.Wu, 1995: Tomographic imaging of lithospheric structures underTaiwan.Earth Planet.Sci.Lett., 133, 517-532, doi: 10.1016/0012-821X(95)00076-O. [Link]

Rice, J. R. and M. P. Cleary, 1976: Some basic stress diffusion solutions for fluid-saturated elastic porous media with compressible constituents. Rev. Geophys., 14, 227-241, doi: 10.1029/rg014i002p00227. [Link]

Rikitake, T., 1968: Earthquake prediction. Earth-Sci.Rev., 4, 245-282, doi: 10.1016/0012-8252(68)90154-2. [Link]

Roeloffs, E. A., 1988: Hydrologic precursors to earthquakes: A review. Pure Appl. Geophys., 126, 177-209, doi: 
10.1007/bf00878996. [Link]

Roeloffs, E. A., E. Quilty, and C. H. Scholtz, 1997: Case 21 water level and strain changes preceding and following the August 4, 1985 Kettleman Hills, California, earthquake. Pure Appl. Geophys., 149, 21-60, doi: 10.1007/ bf00945160. [Link]

Rundle, J. B., D. L. Turcotte, R. Shcherbakov, W. Klein, and C. Sammis, 2003: Statistical physics approach to understanding the multiscale dynamics of earthquake fault systems. Rev. Geophys., 41, 1019, doi: 10.1029/2003RG000135. [Link]

Sato, H., 1986: Temporal change in attenuation intensity before and after the Eastern Yamanashi earthquake of 1983 in Central Japan. J. Geophys. Res., 91, 20492061, doi: 10.1029/jb091ib02p02049. [Link]

Semenov, A. M., 1969: Variations in the travel-time of transverse and longitudinal waves before violent earthquakes. Izv. Earth Phys. (English Transl.), 4, 245-248.

Shin, T.-C., 1993: The calculation of local magnitude from the simulated Wood-Anderson seismograms of the short-period seismograms in the Taiwan area. Terr. Atmos. Ocean. Sci., 4, 155-170, doi: 10.3319/ TAO.1993.4.2.155(T). [Link]

Shin, T.-C. and C.-H. Chang, 2005: Taiwan's seismic observational system. In: Wang, J.-H., C.-Y. Wang, Q.C. Sung, T.-C. Shin, S.-B. Yu, C.-F. Shieh, K.-L. Wen, S.-L. Chung, M. Lee, K.-M. Kuo, K.-C. Chang, and S.-L. Chung (Eds.), The 921 Chi-Chi Major Earthquake, Office of Inter-Ministry Science \& Technology Program for Earthquake and Active-fault Research, National Science Council, Taiwan, 60-82. (in Chinese)

Shin, T.-C. and T.-L. Teng, 2001: An overview of the 1999 Chi-Chi, Taiwan, earthquake. Bull. Seismol. Soc. Am., 91, 895-913, doi: 10.1785/0120000738. [Link]

Shrivastava, A., 2014: Are pre-seismic ULF electromagnetic emissions considered as a reliable diagnostics for earthquake prediction? Curr. Sci., 107, 596-600.

Song, S.-R., W.-Y. Ku, Y.-L. Chen, Y.-C. Lin, C.-M. Liu, L.-W. Kuo, T. F. Yang, and H.-J. Lo, 2003: Groundwater chemical anomaly before and after the Chi-Chi earthquake in Taiwan. Terr. Atmos. Ocean. Sci., 14, 311-320, doi: 10.3319/TAO.2003.14.3.311(T). [Link]

Song, S.-R., Y.-L. Chen, C.-M. Liu, W.-Y. Ku, H.-F. Chen, Y.-J. Liu, L.-W. Kuo, T. F. Yang, C.-H. Chen, T.K. Liu, and M. Lee, 2005: Hydrochemical changes in spring waters in Taiwan: Implications for evaluating sites for earthquake precursory monitoring. Terr. Atmos. Ocean. Sci., 16, 745-762, doi: 10.3319/ TAO.2005.16.4.745(GIG). [Link]

Song, S.-R., W.-Y. Ku, Y.-L. Chen, C.-M. Liu, H.-F. Chen, P. S. Chan, Y.-G. Chen, T. F. Yang, C.-H. Chen, T.-K. Liu, and M. Lee, 2006: Hydrogeochemical anomalies in the springs of the Chiayi area in West-central Taiwan as possible precursors to earthquakes. Pure Appl.
Geophys., 163, 675-691, doi: 10.1007/s00024-0060046-x. [Link]

Teng, T.-L., 1980: Some recent studies on groundwater radon content as an earthquake precursor. J. Geophys. Res., 85, 3089-3099, doi: 10.1029/jb085ib06p03089. [Link]

Tsai, Y.-B., 1986: Seismotectonics of Taiwan. Tectonophysics, 125, 17-37, doi: 10.1016/0040-1951(86)90005-3. [Link]

Tsai, Y.-B., T.-L. Teng, J.-M. Chiu, and H.-L. Liu, 1977: Tectonic implications of the seismicity in the Taiwan region. Mem. Geol. Soc. China, 2, 13-41.

Tsai, Y.-B., T.-L. Teng, Y.-H. Yeh, S.-B. Yu, K.-K. Liu, and J.-H. Wang, 1983: Status of earthquake prediction research in Taiwan, ROC. Bull. Inst. Earth Sci. Acad. Sin., 3, 1-26.

Tsai, Y.-B., J.-Y. Liu, K.-F. Ma, H.-Y. Yen, K.-S. Chen, Y .I. Chen, and C.-P. Lee, 2004: Preliminary results of the iSTEP Program on integrated search for Taiwan earthquake precursors. Terr. Atmos. Ocean. Sci., 15, 545562, doi: 10.3319/TAO.2004.15.3.545(EP). [Link]

Tsai, Y.-B., J.-Y. Liu, K.-F. Ma, H.-Y. Yen, K.-S. Chen, Y.I. Chen, and C.-P. Lee, 2006: Precursory phenomena associated with the 1999 Chi-Chi earthquake in Taiwan as identified under the iSTEP program. Phys. Chem. Earth, 31, 365-377, doi: 10.1016/j.pce.2006.02.035. [Link]

Tsai, Y.-B., J.-Y. Liu, T.-C. Shin, H.-Y. Yen, and C.-H. Chen, 2018: Multidisciplinary earthquake precursor studies in Taiwan: A review and future prospects. In: Ouzounov, D., S. Pulinets, K. Hattori, and P. Taylor (Eds.), Pre-Earthquake Processes: A Multidisciplinary Approach to Earthquake Prediction Studies, Geophysical Monograph Series, Vol. 234, American Geophysical Union, 41-65, doi: 10.1002/9781119156949.ch4. [Link]

Turcotte, D. L., 1991: Earthquake prediction. Annu. Rev. Earth Planet. Sci., 19, 263-281, doi: 10.1146/annurev. ea.19.050191.001403. [Link]

Ustaszewski, K., Y.-M. Wu, J. Suppe, H.-H. Huang, C.-H. Chang, and S. Carena, 2012: Crust-mantle boundaries in the Taiwan-Luzon arc-continent collision system determined from local earthquake tomography and 1D models: Implications for the mode of subduction polarity reversal. Tectonophysics, 578, 31-49, doi: 10.1016/j.tecto.2011.12.029. [Link]

Uyeda, S., T. Nagao, and M. Kamogawa, 2009: Shortterm earthquake prediction: Current status of seismoelectromagnetics. Tectonophysics, 470, 205-213, doi: 10.1016/j.tecto.2008.07.019. [Link]

Uyeda, S., T. Nagao, and M. Kamogawa, 2011: Earthquake precursors and prediction. In: Gupta, H. K. (Ed.), Encyclopedia of Solid Earth Geophysics, Encyclopedia of Earth Sciences Series, Springer, Dordrecht, 
168-178, doi: 10.1007/978-90-481-8702-7_4. [Link]

Venegas-Aravena, P., E. G. Cordaro, and D. Laroze, 2019: A review and upgrade of the lithospheric dynamics in context of the seismo-electromagnetic theory. Nat. Hazards Earth Syst. Sci., 19, 1639-1651, doi: 10.5194/ nhess-19-1639-2019. [Link]

Walia, V., S.-J. Lin, W.-L. Hong, C.-C. Fu, T. F. Yang, K.L. Wen, and C.-H. Chen, 2009: Continuous temporal soil-gas composition variations for earthquake precursory studies along Hsincheng and Hsinhua faults in Taiwan. Radiat. Meas., 44, 934-939, doi: 10.1016/j. radmeas.2009.10.010. [Link]

Walia, V., T. F. Yang, S.-J. Lin, A. Kumar, C.-C. Fu, J.M. Chiu, H.-H. Chang, K.-L. Wen, and C.-H. Chen, 2013: Temporal variation of soil gas compositions for earthquake surveillance in Taiwan. Radiat. Meas., 50, 154-159, doi: 10.1016/j.radmeas.2012.11.007. [Link]

Wallace, R.E., J. F. Davis, and K. C. McNally, 1984: Terms for expressing earthquake potential, prediction, and probability. Bull. Seismol. Soc. Am., 74, 1819-1825, doi: 10.1785/BSSA0740051819. [Link]

Wang, C.-H., C.-Y. Wang, C.-H. Kuo, and W.-F. Chen, 2005a: Some isotopic and hydrological changes associated with the 1999 Chi-Chi earthquake, Taiwan. The Island Arc, 14, 37-54, doi: 10.1111/j.14401738.2004.00456.x. [Link]

Wang, J.-H., 1988a: b values of shallow earthquakes in Taiwan. Bull. Seismol. Soc. Am., 78, 1243-1254, doi: 10.1785/BSSA0780031243. [Link]

Wang, J.-H., 1988b: Temporal change in duration ratios for foreshocks and aftershocks of a moderate Taiwan earthquake. Proc. Geol. Soc. China, 31, 99-110.

Wang, J.-H., 1989: The Taiwan Telemetered Seismographic Network. Phys. Earth Planet. Inter., 58, 9-18, doi: 10.1016/0031-9201(89)90090-3. [Link]

Wang, J.-H., 1992: Magnitude scales and their relations for Taiwan earthquakes: A review. Terr. Atmos. Ocean. Sci., 3, 449-468, doi: 10.3319/TAO.1992.3.4.449(T). [Link]

Wang, J.-H., 1998: Studies of earthquake seismology in Taiwan during the 1897-1996 period. J. Geol. Soc. China, 41, 291-336.

Wang, J.-H., 2016: A mechanism causing $b$-value anomalies prior to a mainshock. Bull. Seismol. Soc. Am., 106, 1663-1671, doi: 10.1785/0120150335. [Link]

Wang, J.-H., 2019: A review on studies of the 1999 ChiChi earthquake for resolving the debatable problems in earthquake physics. Terr. Atmos. Ocean. Sci., 30, 739756, doi: 10.3319/TAO.2019.03.26.01. [Link]

Wang, J.-H., 2021a: Piezoelectricity as a mechanism on generation of electromagnetic precursors before earthquakes. Geophys. J. Int., 224, 682-700, doi: 10.1093/ gji/ggaa429. [Link]

Wang, J.-H., 2021b: A review on precursors of the $1999 \mathrm{M}_{\mathrm{w}}$
7.6 Chi-Chi, Taiwan, earthquake. Terr. Atmos. Ocean. Sci., 32, doi: 10.3319/TAO.2021.03.24.01. [Link]

Wang, J.-H. and S. Miyamura, 1990: Comparison of several instrumentally-determined magnitude scales for Taiwan earthquakes (1900-1978). Proc. Geol. Soc. China, 33, 89-108

Wang, J.-H., K.-C. Chen, and T.-Q. Lee, 1994: Depth distribution of shallow earthquakes in Taiwan. J. Geol. Soc. China, 37, 125-142.

Wang, J.-H., C.-Y. Wang, Q.-C. Sung, T.-C. Shin, S.-B. Yu, C.-F. Shieh, K.-L. Wen, S.-L. Chung, M. Lee, K.-M. Kuo, K.-C. Chang, and S.-L. Chung, 2005b: The 921 Chi-Chi Major Earthquake, Office of Inter-Ministry Science \& Technology Program for Earthquake and Active-fault Research, National Science Council, Taiwan, 583 pp. (in Chinese)

Wang, J.-H., K.-C. Chen, P.-L. Leu, and J.-H. Chang, 2015: $b$-values observations in Taiwan: A review. Terr. Atmos. Ocean. Sci., 26, 475-492, doi: 10.3319/ TAO.2015.04.28.01(T). [Link]

Wang, J.-H., K.-C. Chen, P.-L. Leu, and C.-H. Chang, 2016: Precursor times of abnormal $b$-values prior to mainshocks. J. Seismol., 20, 905-919, doi: 10.1007/ s10950-016-9567-7. [Link]

Wen, S., C.-H. Chen, H.-Y. Yen, T.-K. Yeh, J.-Y. Liu, K. Hattori, H. Peng, C.-H. Wang, and T.-C. Shin, 2012: Magnetic storm free ULF analysis in relation with earthquakes in Taiwan. Nat. Hazards Earth Syst. Sci., 12, 1747-1754, doi: 10.5194/nhess-12-1747-2012. [Link]

Wen, S., C.-H. Chen, Y .-J. Ji, Y.-Z. Chang, and C.-H. Chen, 2015: The seismogenic deformation and $Q_{p}$ temporal variation before the M6.2 Mingjen earthquake, Taiwan. J. Asian Earth Sci., 114, 403-413, doi: 10.1016/j. jseaes.2015.06.011. [Link]

Wen, Y.-Y. and C.-C. Chen, 2017: Seismicity variations prior to the $2016 \mathrm{M}_{\mathrm{L}} 6.6$ Meinong, Taiwan earthquake. Terr. Atmos. Ocean. Sci., 28, 739-744, doi: 10.3319/ TAO.2016.12.05.01. [Link]

Woith, H., G. M.Petersen, S. Hainzl, and T. Dahm, 2018: Review: Can animals predict earthquakes? Bull. Seismol. Soc. Am., 108, 1031-1045, doi: 10.1785/0120170313. [Link]

Wu, F. T., 1975: Gas well pressure fluctuations and earthquakes. Nature, 257, 661-663, doi: 10.1038/257661a0. [Link]

Wu, F. T., 1978: Recent tectonics of Taiwan. J. Phys. Earth, 26, S265-S299, doi: 10.4294/jpe1952.26.supplement_ s265. [Link]

Wu, F. T. and C. C. Feng, 1975: Gas well pressure fluctuation as an earthquake precursor. Petrol. Geol. Taiwan, 12, 141-148.

Wu, K., M. Yue, H. Wu, X. Cao, H. Chen, W. Huang, K. Tian, and S. Lu, 1976: Certain characteristics of 
Haicheng earthquake $(\mathrm{M}=7.3)$ sequence. Chin. J. Geophys., 19, 95-109.

Wu, Y.-H., C.-C. Chen, and J. B. Rundle, 2008: Precursory seismic activation of the Pingtung (Taiwan) offshore doublet earthquakes on 26 December 2006: A pattern informatics analysis. Terr. Atmos. Ocean. Sci., 19, 743749, doi: 10.3319/TAO.2008.19.6.743(PT). [Link]

Wu, Y.-H., C.-C. Chen, J. B. Rundle, and J.-H. Wang, 2012: Regional dependence of seismic migration patterns. Terr. Atmos. Ocean. Sci., 23, 161-170, doi: 10.3319/ TAO.2011.10.21.01(T). [Link]

Wu, Y.-M. and C.-C. Chen, 2007: Seismic reversal pattern for the 1999 Chi-Chi, Taiwan, $M_{\mathrm{W}} 7.6$ earthquake. Tectonophysics, 429, 125-132, doi: 10.1016/j.tecto.2006.09.015. [Link]

Wu, Y.-M. and L.-Y. Chiao, 2006: Seismic quiescence before the 1999 Chi-Chi, Taiwan, $M_{\mathrm{w}} 7.6$ earthquake. Bull. Seismol. Soc. Am., 96, 321-327, doi: 10.1785/0120050069. [Link]

Wu, Y.-M., Y.-J. Hsu, C.-H. Chang, L. S. Teng, and M. Nakamura, 2010: Temporal and spatial variation of stress field in Taiwan from 1991 to 2007: Insights from comprehensive first motion focal mechanism catalog. Earth Planet. Sci. Lett., 298, 306-316, doi: 10.1016/j. eps1.2010.07.047. [Link]

Xia, Y., J.-Y.T.Liu, X.Cui, J.Li, W.Chen, and C.Liu, 2011: Abnormal infrasound signals before $92 M \geq 7.0$ worldwide earthquakes during 2002-2008. J. Asian Earth Sci., 41, 434-441, doi: 10.1016/j.jseaes.2010.04.015. [Link]
Yang, T. F., V. Walia, L. L. Chyi, C.-C. Fu, C.-H. Chen, T.-K. Liu, S.-R. Song, C.-Y. Lee, and M. Lee, 2005: Variations of soil radon and thoron concentrations in a fault zone and prospective earthquakes in SW Taiwan. Radiat. Meas., 40, 496-502, doi: 10.1016/j.radmeas.2005.05.017. [Link]

Yang, T. F., C.-C. Fu, V. Walia, C.-H. Chen, L. L. Chyi, T.K. Liu, S.-R. Song, M. Lee, C.-W. Lin, and C.-C. Lin, 2006: Seismo-geochemical variations in SW Taiwan: Multi-parameter automatic gas monitoring results. Pure Appl. Geophys., 163, 693-709, doi: 10.1007/ s00024-006-0040-3. [Link]

Yeh, Y.-H., Y.-B. Tsai, and T.-L. Teng, 1981: Investigations of geomagnetic total intensity in Taiwan from 1979 to 1981. Bull. Inst. Earth Sci. Acad. Sin., 1, 157-187.

Yen, H.-Y., C.-H. Chen, Y.-H. Yeh, J.-Y. Liu, C.-R. Lin, and Y.-B. Tsai, 2004: Geomagnetic fluctuations during the 1999 Chi-Chi earthquake in Taiwan. Earth Planets Space, 56, 39-45, doi: 10.1186/bf03352489. [Link]

Yu, G.-K. and B. J. Mitchell, 1988: A study of the nontectonic influences on groundwater level fluctuations. Proc. Geol. Soc. China, 31, 111-124.

Yu, S.-B., H.-Y. Chen, and L.-C. Kuo, 1997: Velocity field of GPS stations in the Taiwan area. Tectonophysics, 274, 41-59, doi: 10.1016/S0040-1951(96)00297-1. [Link]

Zeng, X., J.-Y. Liu, Y. Lin, and C. Xu, 2002: The evolution of dynamic images of geomagnetic field and strong earthquake. Journal of Atmospheric Electricity, 22, 191-205, doi: 10.1541/jae.22.191. [Link] 